\title{
EL MONUMENTO FUNERARIO DE LA CALERILLA DE HORTUNAS (REQUENA, VALENCIA)
}

\author{
POR \\ ASUNCIÓN MARTÍNEZ VALLE \\ Museo Municipal de Requena
}

RESUMEN.

Presentamos en este artículo la reconstrucción del monumento funerario romano de La Calerilla de Hortunas; se trata de un ara con pulvini, de Domitia lusta, cuya construcción originó una interesante necrópolis de cremación de ámbito rural. El estudio de este monumento plantea una serie de cuestiones relacionadas con su tipología y con la problemática que los altares con pulvini presentan en la península ibérica.

\section{SUMMARY}

We present in this article the reconstruction of the Roman funerary monument in the Calerilla of Hortunas. Here we see the altar with pulvini of Domitia lusta, whose construction gave origin to an interesting cremation necropolis in a rural settlement. The study of this monument brings up a series of questions associated with typology and with the problems that pulvini altars present on the Iberian Peninsula.

\section{INTRODUCCIÓN}

El yacimiento de La Calerilla de Hortunas' se conoce desde los años 40 , cuando se construye la

\footnotetext{
'La redacción de este estudio ha contado con diversas aportaciones, entre ellas las del Prof. C. F. Iuliani de la Universidad de Roma. A los Profs. J. L. Jiménez, P. P. Ripollès y L. Abad, de
}

... vetat ex agro culto eove, qui coli possit, ut mortuorum corpora sine detrimento vivorum recipiat, ea potissimum ut compleatur, quae autem terra fruges ferre et ut mater cibos suppeditare possit, eam ne quis nobis minuat neve vivos neve mortuus.

(de leg. 2, 67) carretera que desde Hortunas se dirige a Yátova y se modifica el trazado del antiguo camino que discurría paralelo al cauce del río ${ }^{2}$. En 1989 se realizó una nueva remoción del terreno para un cambio de cultivo en una parcela de este mismo paraje. El desfonde del campo, realizado con un tractor, afectó en gran medida al área central del yacimiento, exhumando numerosos restos arquitectónicos, fragmentos cerámicos y huesos humanos que evidenciaban la destrucción de lo que en su momento fue una necrópolis. Poco tiempo después se inicio una intervención arqueológica de salvamento para determinar las características del yacimiento y el deterioro que en él se había producido. Las campañas realizadas desde 1990 nos han permitido definir las características generales de este yacimiento, todavía en

\footnotetext{
las Universidades de Valencia y Alicante, respectivamente, debemos la lectura crítica del original y las múltiples sugerencias, aunque sólo a mi corresponde la responsabilidad de las ideas que se reflejan en este trabajo. A nuestro amigo J. J. Castellano Castillo debemos la elaboración de todos los dibujos y al Dr. J. Arce y a la familia Benedetti, las calurosas acogidas en Roma, las cuales nos han permitido acceder con suma facilidad a las bibliotecas de las academias arqueológicas.

${ }^{2}$ A. Cárcel Ramos, Las aldeas de Hortunas y El Rebollar 1800 1981, Valencia 1982, p. 131.
} 
proceso de excavación; la necrópolis, como a continuación trataremos de demostrar, comenzó a utilizarse a mediados del siglo I d.C. con la construcción de un monumento funerario, que será el objeto de este estudio, y varias tumbas de cremación en torno a él. Tras un periodo de abandono, que relacionamos con la destrucción de las tumbas más monumentales de incineración, esta necrópolis comenzó de nuevo a utilizarse a partir del siglo ıI d.C.; pero, desde este momento, ya se adoptó el rito de la inhumación, sin que se pueda determinar con precisión la cronología de los últimos enterramientos, por la ausencia de ajuares que permitan concretar su datación.

\section{SITUACIÓN DEL YACIMIENTO Y EMPLAZAMIENTO DE LA NECRÓPOLIS}

El yacimiento de La Calerilla está situado en un pequeño valle ${ }^{3}$ en el extremo suroriental del término municipal de Requena, a dos kilómetros de la pedania de Hortunas, junto a la carretera comarcal que une la Hoya de Buñol con el altiplano de Requena-Utiel ${ }^{4}$ (fig. 1).

El valle de Hortunas está atravesado por el río Magro, afluente del Júcar, que desde Requena discurre encajado entre bancos calizos y a su paso por la aldea de Hortunas se abre para dar lugar a una fértil vega de origen cuaternario, limitada y protegida por los montes de la Herrada al norte y al sur por las estribaciones de la Sierra Martés y de la Sierra Le $^{5}$. Esta circunstancia, junto con su orientación esteoeste, propicia la existencia de un microclima de características más benignas que las que le correspondería por su altitud ${ }^{6}$, haciendo de este valle un enclave muy apropiado para las actividades agropecuarias.

En época ibérica es cuando se produce una ocupación generalizada en la zona, según se deduce del número de yacimientos conocidos y de su dispersión ${ }^{7}$. Esta intensa ocupación podría ser el motivo

${ }^{3}$ Tomando la cota 600 , posee una superficie aproximada de $450 \mathrm{Ha}$.

4 El yacimiento se localiza en las coordenadas 669.600 . 4.361.500 de la hoja 27-28 del mapa 720 (editado por el S.G.E.) escala 1:50.000, del año 1981.

'J. Piqueras Haba, Geografia de Requena-Utiel, Requena, 1990. pp. 101-105.

- $540 \mathrm{~m}$ sobre el nivel del mar.

? No ha sido publicado ningún yacimiento de este valle y la información a la que nosotros aludimos procede de las fichas de inventario de yacimientos que hemos realizado en la comarca de Requena-Utiel para la Consellería de Cultura de la Generalidad Valenciana.

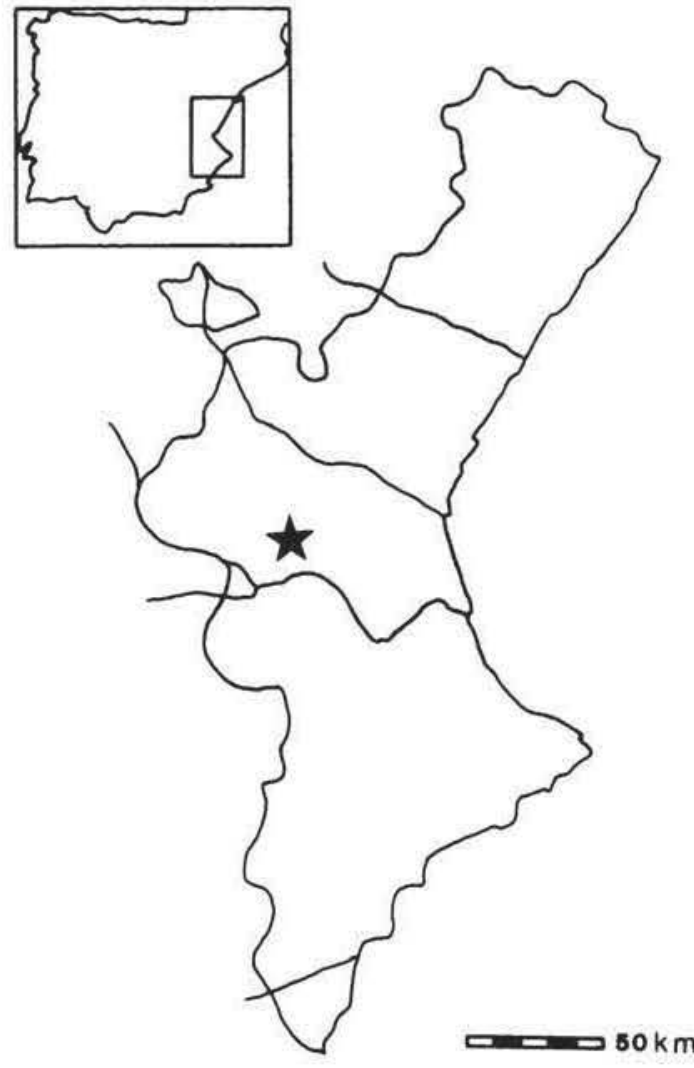

Figura 1.-Situación del yacimiento de La Calerilla.

por el que documentamos en las tumbas de incineración de La Calerilla una fuerte tradición indigena, tanto en el ritual como en la decoración de algunas urnas funerarias ${ }^{8}$. La tradición ibérica, que perdura en los primeros siglos de nuestra era, viene avalada, a su vez, por el reciente hallazgo, a pocos kilómetros del valle, de una inscripción funeraria del siglo "I d.C., sobre la que se trazó un esgrafiado ibérico de más de ocho signos en la parte superior de la cartela ${ }^{9}$.

En lo referente al emplazamiento de la necrópolis, ésta se halla situada en la desembocadura de un pequeño barranco que, en la actualidad, se encuentra totalmente aterrazado; este emplazamiento, en un principio, nos sorprendió a causa de los problemas que la evacuación de aguas y su arrastre pudieron haber ocasionado. Sin embargo, sobre la situación de las necrópolis y su relación con la tierra

\footnotetext{
* Urnas con bandas pintadas, una con un friso de motivos fitomorfos y otra con el friso decorado con tríos de eses, de formas similares a las aparecidas en la necrópolis de La Torre Ciega de Cartagena; véase J. M. Abascal Palazón, La cerámica pintada romana de tradición indigena en la Peninsula Ibérica, Madrid 1986 , p. 30 , donde se dan otros paralelos para este tipo de urnas.

A. Martinez Valle, «Dos esgrafiados ibéricos sobre una estela romana de Requena (Valencia)", Saguntum 26, 1993, pp. 247-251.
} 
cultivable, Cicerón en su tratado de legibus, remitiéndose a Platón, quien a su vez recoge la tradición de los interpretes religionum, hace una interesante aclaración que bien puede servir para comprender la ubicación que tiene la necrópolis de la Calerilla, «... que los sepulcros no ocupen ninguna parte de un campo que pueda ser cultivado, para que en ningún modo, el culto de los muertos pueda perjudicar de algún modo a los vivos, porque nadie vivo o muerto debe disminuir la tierra fecunda, que como una madre proporciona sus frutos» ${ }^{10}$.

\section{EL MONUMENTO FUNERARIO: SU ESTRUCTURA Y CIMENTACIÓN}

La excavación puso al descubierto los restos incompletos de una plataforma de mampostería que, debido a su situación en la parte más elevada del campo, quedó muy afectada por el arado (fig. 2). Esta plataforma es el único resto del monumento que ha permanecido in situ después del desfonde y, sobre ella, se alzaria la parte visible del edificio, sin que podamos tener una completa seguridad de las dimensiones que tendría. La única medida que se ha conservado integra, después del desfonde, corresponde a la fachada noreste y es de $5,15 \mathrm{~m}$; por su parte sureste conserva $3,65 \mathrm{~m}$, casi su totalidad, faltando la última piedra de la hilada cuyo hueco era todavia visible, en el momento de la excavación.

Con anterioridad al desfonde la plataforma de mamposteria ya se encontraba parcialmente destruida por dos fosos excavados, uno en la cara norte y otro en el centro. Estos dos fosos se encontraban colmatados con material procedente del derrumbe del edificio, en un momento anterior a la formación de los niveles estratigráficos, por lo que podrían estar relacionados con la profanación y destrucción del monumento cuando todavía permanecia en pie, ya que los materiales que los rellenaban no se vieron alterados por la remoción que produjo el desfonde.

La excavación del foso que existe en la cara noreste del monumento nos proporcionó interesantes fragmentos decorados de su fachada " y dejó al descubierto el perfil completo de la plataforma de mampostería y la sección de la cimentación correspondiente a este lado (fig. 2).

En el perfil que quedó al descubierto se puede

\footnotetext{
${ }^{10}$ Cicerón, de leg. 2, 67. Véase: R. M. Fernández Fernández. "La ley de la Colonia Genitiva Iulia en la experiencia romana sobre las comunidades. Urso 73,74 : de las XII tablas al código de Justiniano", Estudios sobre Urso, Sevilla, 1989, p. 86.

"En este foso recuperamos la inscripción funeraria, varios fragmentos de las molduras y de la cornisa de ovas y dardos.
}

apreciar que, en los laterales de esta plataforma, existe una gran concentración de grava por debajo de los bloques que regularizan el terreno, no asi en su parte central ni en la fachada suroeste, donde sólo se ve la hilada de piedra sobre el terreno virgen. Esta desigualdad, pensamos que estaría en relación con el reparto de cargas que los laterales de la plataforma tendrian que soportar y parece lógica si pensamos que este monumento se encuentra emplazado en la parte central de un barranco y que necesitaría mayor cimentación en la fachada que está frente a la desembocadura; por otra parte, según la reconstrucción del monumento que proponemos, en esta fachada estaría situada la puerta de acceso a la cámara sepulcral por lo que al estar libre de cargas, en la parte central sólo dispondría de la hilada de regularización con el fín de fijar los niveles.

El foso que existe en posición más o menos central, al igual que el que se encontraba destruyendo parte de la cara norte, también se encontraba colmatado con material procedente del derrumbe del edificio. El mal estado en que se encontraba el monumento en el momento de la excavación, impide una interpretación clara sobre la funcionalidad que pudo haber tenido este foso, posiblemente en relación con un depósito fundacional profanado como se ha podido documentar en la tumba de Iulius Felix $^{12}$, o un loculus destruido como ocurre en uno de los monumentos de Liria ${ }^{13}$.

La reconstrucción completa de la plataforma de mampostería la hemos efectuado sobre la base de las medidas in situ y de la presencia de cuatro agujeros de poste que la delimitan por sus lados. Estos agujeros, junto con los que también existen alrededor del monumento, pensamos que serían los que formarian parte del sistema de andamiaje utilizado para levantar el edificio ${ }^{14}$. De esta manera, la plataforma de cimentación tendria, en sus lados más largos, 5,15 m y unos 3,90 m por los más cortos (fig. 2); aunque como es lógico ello no quiere decir que éstas fueran las medidas de la base del monumento.

\section{Los escalones del zócalo}

Junto a la cara noreste de la plataforma de cimentación documentamos dos fragmentos de silla-

\footnotetext{
12 N. Ferchiou, "Le Mausolée de C. Iulius Felix, à Henchir Messaouer", RM 94, 1987, p. 423.

${ }^{13}$ L. Rivas Huesa y otros, «Nuevas aportaciones en torno a la arquitectura funeraria romana: el edificio $n^{\circ} 2$ de la necrópolis de Lliria (Valencia)", Lauro 5, 1991, p. 164.

it Estos agujeros del sistema de andamiajes también se han documentado en Vilde (Soria), véase C. Garcia Merino, "Un sepulcro romano turriforme en La Meseta Norte. El yacimiento arqueológico de Vilde (Soria)", BSEAA XLIII, 1977, p. 41.
} 


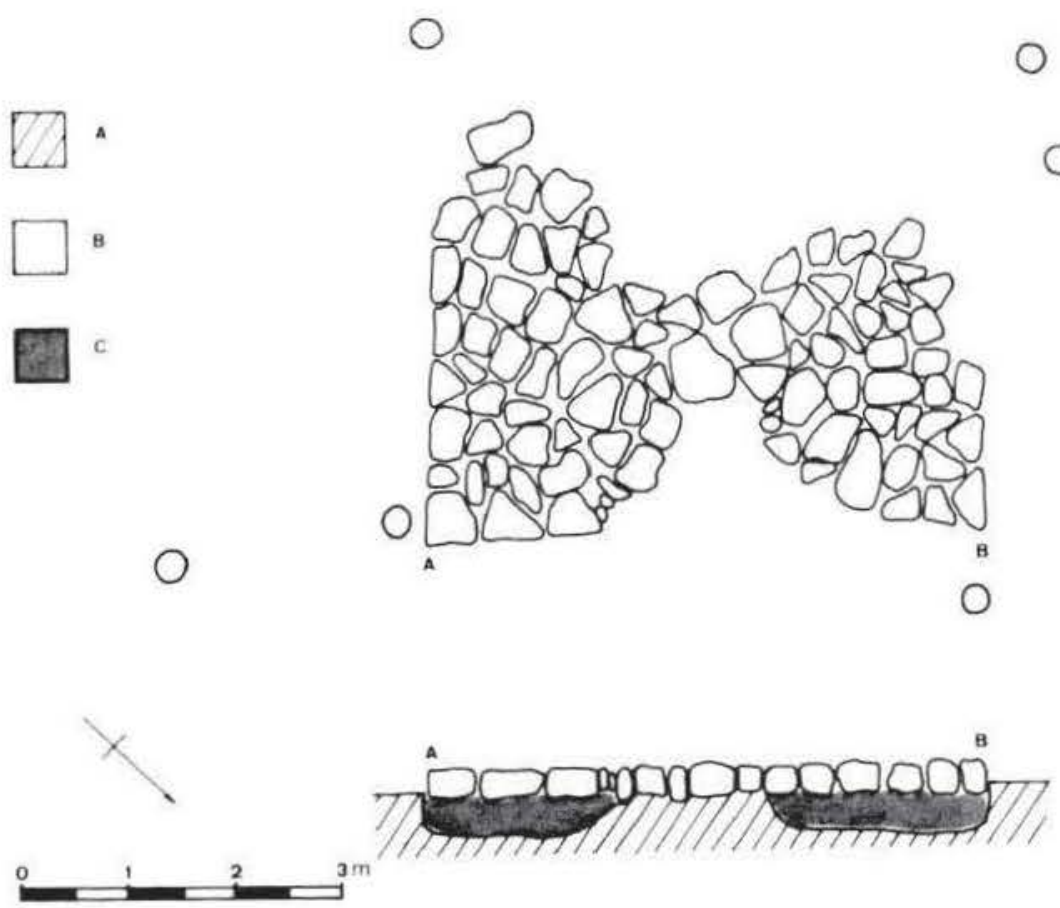

Figura 2. Planta y perfil de la cimentacion del monumento. A micel del suelo vegetal. B parte de la planta reconstruida: (c cimentaciones

res, realizados en arenisca de grano grueso, color amarillo y procedencia local, que el arado no desplazo por encontrarse hundidos en el foso que destruyo la planta por este lado. Fstos bloques conservan una incision longitudinal bien marcada a partir de la que se pueden ver otras similares, labradas hasta su borde interno. Las medidas que conservan son: $40 \mathrm{~cm}$ desde la linea a su lado interno y $20 \mathrm{~cm}$ al lado externo; la altura del bloque es de $29 \mathrm{~cm}$.

Junto a los restos de la planta, a nivel superficial y por su lado oeste, quedaron dos bloques más que el arado sólo consiguió desplazar a poca distancia debido a sus dimensiones. Estos bloques parecen estar completos, y presentan idéntica factura que los que hemos comentado, con medidas similares.

Las marcas y las pequeñas incisiones que presentan estos bloques, permiten suponer que otros superiores descansarian sobre ellos. La linea recta que se aprecia en estos casos marcaria el inicio del escalón superior y las pequeñas incisiones se labrarian para fijar con mayor adherencia el mortero que uniria los peldaños, quedando cubiertas con el bloque superior (fig. 3).

Estos cuatro bloques que acabamos de describir son los únicos relacionados con la excavación arqueológica y que con seguridad pertenecieron al

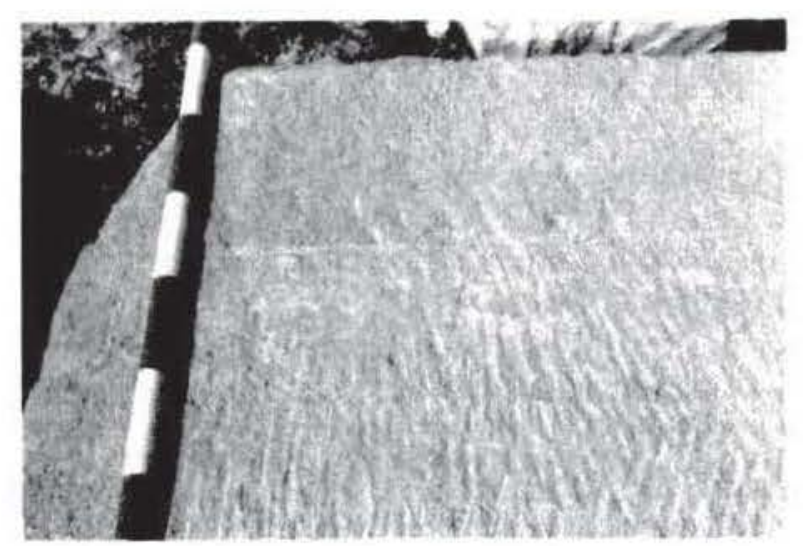

Figura 3.-Peldanos del monumento (hrepis) con las marcas de un escalón superior. 
zócalo del monumento. Pero el propietario del terreno nos comentó que se había extraido mucha piedra de este campo, reutilizándola en muros de contención y otros menesteres; asi, en la aldea, recuperamos cuatro bloques más que, por el tipo de piedra y factura, debieron formar parte del zócalo del monumento funerario.

La existencia de estos bloques nos hace pensar que el monumento se alzaría sobre un krepis, zócalo escalonado de arenisca; los bloques de 28 y 29 $\mathrm{cm}$ de grosor formarian parte de la primera hilada del zócalo, ocupando toda la superficie de la plataforma de mampostería del monumento. De este modo, situaríamos los bloques de distintas superficies que hemos encontrado reutilizados en la aldea: los que muestran la marca de un bloque superior formarian parte de los escalones y el resto, en los que no se aprecian estas marcas, cubririan la parte interna de toda la plataforma de cimentación. Sobre esta primera hilada de $28-29 \mathrm{~cm}$ de grosor, se situarían los bloques más pequeños de $15 \mathrm{~cm}$, de los que sólo hemos recuperado uno en Hortunas.

El nivel del suelo en época romana debió destruirse al desfondarse el campo, pero creemos posible que la primera hilada de bloques del monumento permaneciera parcialmente oculta, dejando visible, aproximadamente, $15 \mathrm{~cm}$, medida que se correspondería con la altura de los escalones del nivel superior.

\section{El alzado del monumento}

El cuerpo del monumento fue construido con otro tipo de material que el que se utilizó en los escalones del zócalo y en la cimentación del edificio ${ }^{15}$. Existen suficientes testimonios para afirmar que éste se levantó con caliza terciaria de origen lacustre de color gris, de procedencia local ${ }^{16}$, muy fácil de tallar. Por los restos recuperados en el transcurso de la excavación, suponemos que el edificio tendría una estructura interna de piedra y mortero, de la que sólo han quedado fragmentos de piedra caliza en los que se puede apreciar este mortero de cal adherido. Esta estructura de opus caementicium estaría forrada por bloques del mismo tipo de piedra, bien tallados, que formarian un paramento de opus quadratum de esquema similar al que se puede ver en los monumen-

\footnotetext{
is Hemos encontrado otros monumentos que, por imperativos técnicos, también utilizaron diferentes tipos de piedra. Véase $\mathrm{N}$. Ferchiou, op. cit. nota 12, p. 423 y «Les mausolées augustéens d'Assuras" MEFRA 99, 1987, p. 785; L. Rivas Huesa y otros, op. cit. nota 13 p. 160.

${ }^{16}$ Existen afloramientos de este tipo de caliza junto al barranco de La Calerilla, a escasa distancia del monumento.
}

tos funerarios de Llíria ${ }^{17}$ o en el del centro escolar José Romeu de Sagunto ${ }^{18}$. Pertenecientes a este recubrimiento, que suponemos debió formar parte del alzado del edificio, con alguna de sus caras pulida y alisada, recuperamos en superficie un buen número de bloques fragmentados que el arado debió de partir y arrastrar por el campo, dada la mala calidad y el escaso peso de este tipo de piedra.

Algunos de estos bloques conservan parte de sus medidas completas; lo cual, junto con el tipo de piedra, con las marcas que los instrumentos de trabajo dejaron sobre ellas y, sobre todo, con el acabado general, nos ha permitido identificar seis que con seguridad debieron pertenecer a un edificio de opus quadratum bien realizado. El tamaño de estos sillares es diverso y pensamos que estaría relacionado con su lugar de emplazamiento en el monumento y con el peso que soportarían en el reparto de cargas del edificio.

\section{LA DECORACIÓN DEL MONUMENTO}

\section{El zócalo de la base}

Junto a los restos conservados de la planta y formando parte del relleno que colmataba la fosa excavada en la cara noreste del edificio, recuperamos varios fragmentos de los sillares moldurados que adornarian el monumento por su parte inferior (fig. 4). Estos bloques están realizados con piedra caliza gris de procedencia local y aparecen fracturados, pero todos conservan parte del perfil de la moldura.

Los diferentes fragmentos conservados presentan un esquema similar, pero en el perfil de las molduras se aprecian ligeras diferencias. Dos de estos fragmentos son más similares; el perfil que conserva el más completo es, desde arriba: filete, óvalo, filete, caveto y filete, estando fracturada la moldura en este punto. Por el espacio que ha quedado en el bloque y por la estructura de otro fragmento conservado, suponemos que, continuaría la moldura por su parte inferior con otro óvalo y otro filete, guardando así una simetría (fig 5). Los otros dos bloques restantes muestran ligeras diferencias respecto a éstos, pero la decoración de la moldura presenta un esquema similar.

Al recuperar alguno de estos bloques moldurados entre el material removido y arrastrado por el

\footnotetext{
${ }^{17}$ L. Rivas Huesa y otros, op. cit. nota 13 p. 167.

18 J. L. Jiménez Salvador, «El monumento funerario romano situado en el centro escolar "José Romeu» de Sagunto" Estudios de Arqueologia Ibérica y Romana. Homenaje a Enrique Pla. Trabajos Varios 89, Valencia 1992, pp. 539-554.
} 


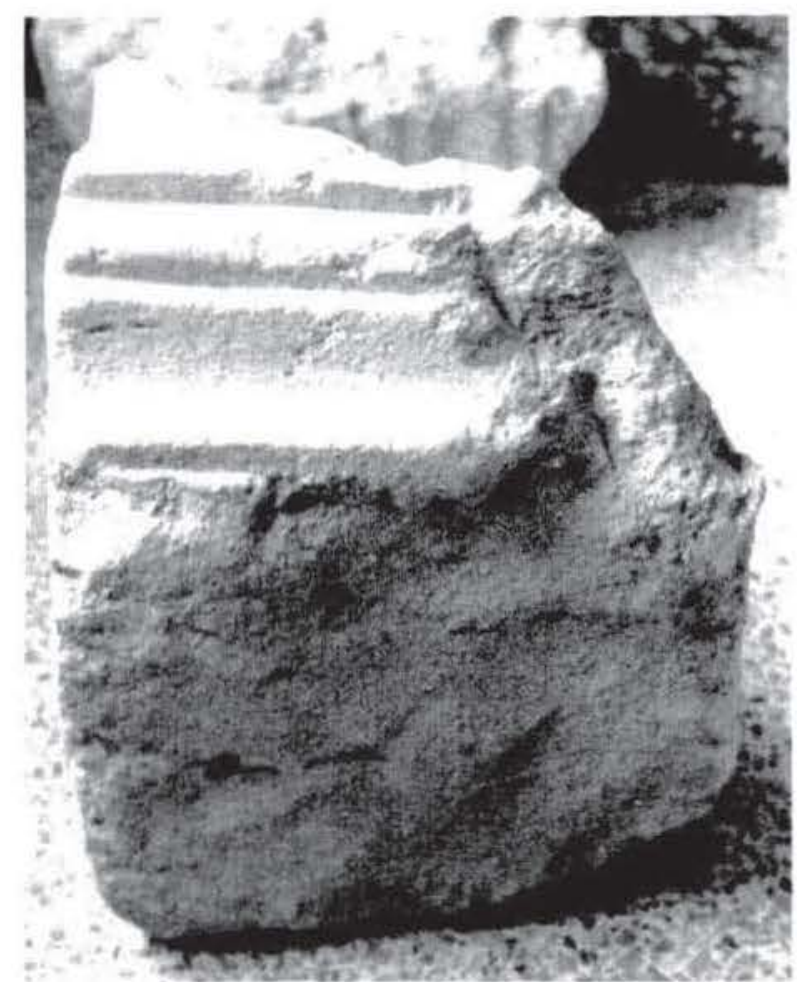

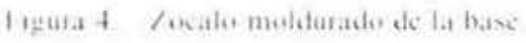

arado, no podemos asegurar que todos cllos pertenecieran al monumento de Demiria Iusfa pero. al presentar un misme esquema, crecmos posible que asi fuera. Otras piezas decoradas del monumento. como el capitel de pilastra o el erote que acompaña la inscripcion. muestran también defectos de labra y asi pensamos que los fragmentos que hemos recuperado del rocalo de la base posiblemente se labraran por separado. lo que explicaria las diferencias señaladas ${ }^{40}$.

\section{El capitel de pilastra}

En el lado este de la planta del edificio, entre el material que el arado removió, recuperamos un fragmento de capitel de pilastra. labrado en la piedra caliza gris, de origen local, con la que se construyó el cuerpo del monumento: este fragmento es. hasta la actualidad, el único indicio que se conserva de los capiteles que tendria el edificio (fig. 6).

El fragmento en cuestion formaria parte de un angulo del monumento. pues presenta decoración

\footnotetext{
"16 Fis mismo ocurre en un monumento funcrario de epoca augustea del norte de Afriea, donde las piezas de la base de zocalo presentan claras discontinuidades entre ellas, apreciandose ligeras diferencias en el perfil. Vease, N Ferchou. op, cit nota 15, p, $\times 03$.
}

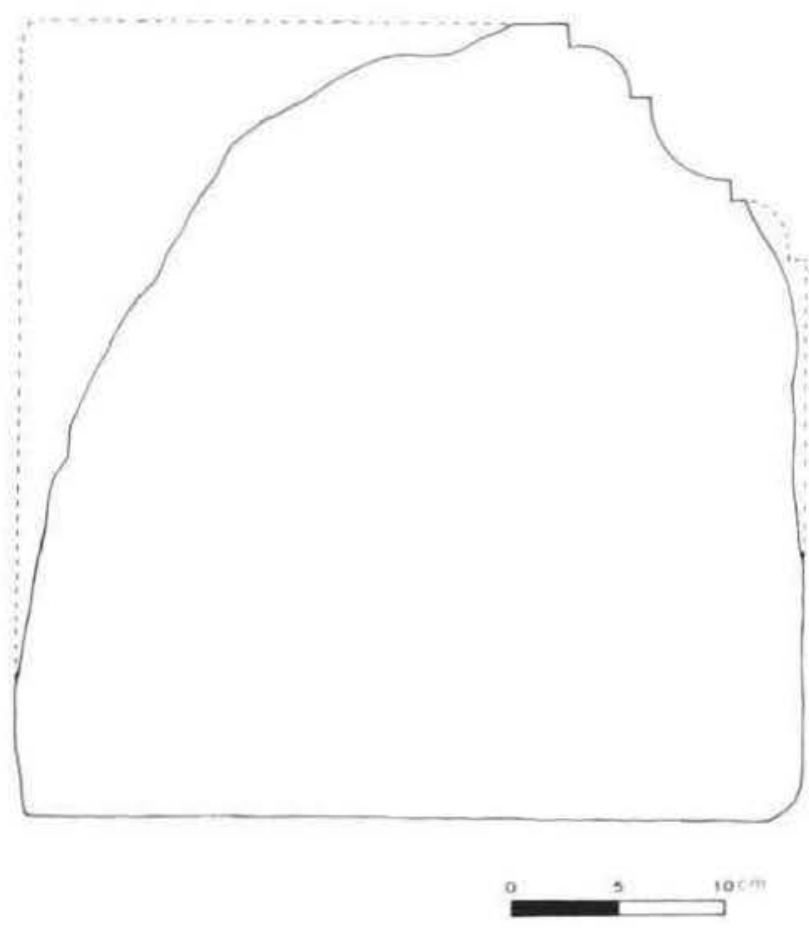

Iiguris 5 Reconstruceion ideal del perfil de la moldura de la bave

en dos de sus caras, aunque una de ellas se encuentra bastante deteriorada. En su parte mas completa. la de la derecha. la decoracion del capitel se mantiene en buen estado. Suponemos que la decoracion del capitel estaria formada, en su parte inferior, por dos coronas de hojas de acanto, La primera corona. ima folia, estaria constituida por dos hojas de acanto de la que sólo se conservan tres lobulos de la hoja de la parte derecha. L a segunda corona, sectunda folia. tendria tres hojas de acanto, dos laterales y una central; la que corresponderia al lateral i/quierdo se ha perdido.

Cada una de las hojas de acanto está compuesta de una nervadura central. de sección en V. que se

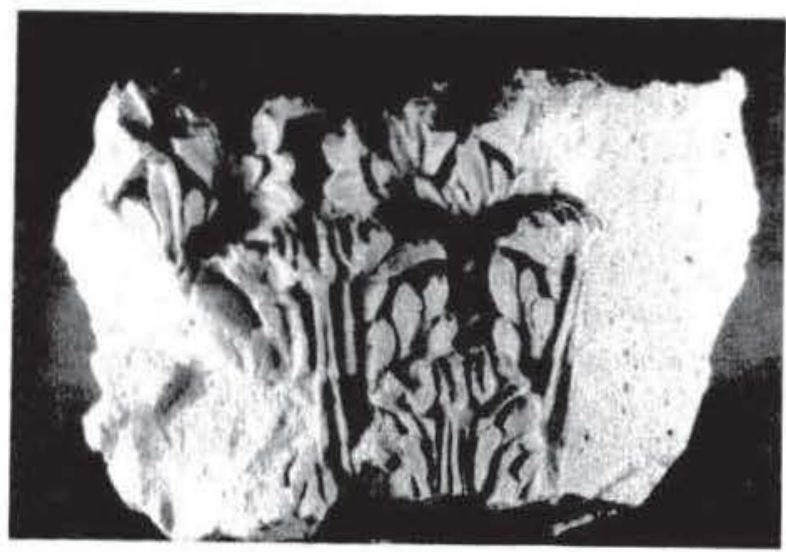

Figura 6. Fragmento del capitel de pilastra. 


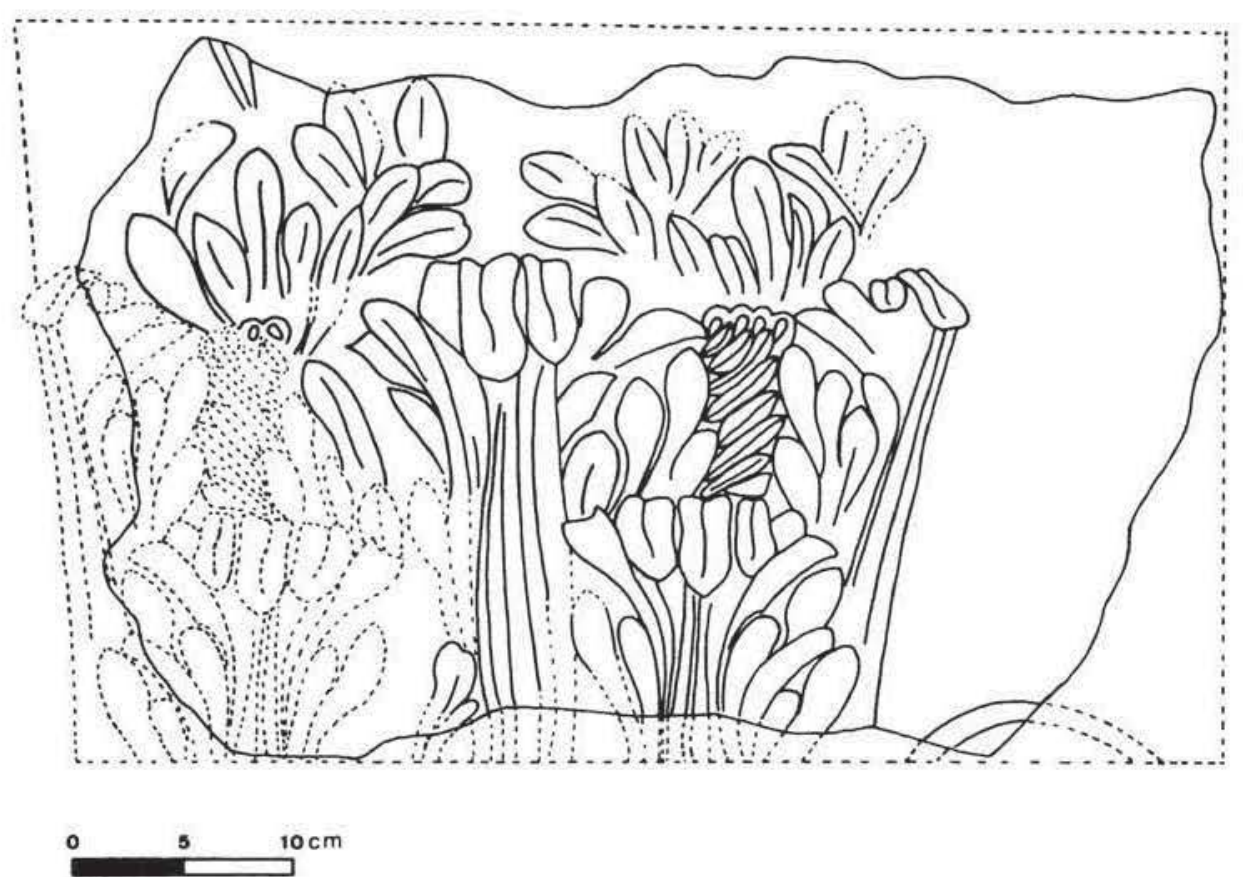

Figura 7.- Reconstrucción de la parte inferior del capitel con el inicio de la guirnalda.

encuentra flanqueada por otras dos paralelas de idénticas características, dando la impresión de que la hoja está dividida en tres partes. Las hojas de las dos coronas de acanto están formadas por lóbulos de cinco hojitas prominentes, flexibles y bien separadas del kalathos, con una pequeña nervadura, en algunos casos, que se prolonga hasta su nacimiento. De la parte central de la hoja de la primera corona parten los caulículos que son rectos, verticales, semicilíndricos y estriados de forma oblicua y paralela, con ausencia de orla en su terminación. Estos, alineados con las hojas de la segunda corona, aparecen muy diferenciados, lo que separa a este capitel de modelos itálicos. El cáliz central presenta una hoja de acanto que reproduce las hojas de la corona, sobresaliendo la hojita central del lóbulo inferior sobre las otras. De la parte posterior de este lóbulo, que se encuentra ligeramente desplazado por defecto de la labra, surgen otros dos lóbulos de acanto que se cierran ligeramente por su parte interna; la parte más externa del lóbulo interno se enfrenta simétricamente a la que procede del cáliz izquierdo, sobre la parte media de la hoja central de la segunda corona.

En el extremo inferior del bloque, en la parte interna de esta cara mejor conservada puede verse labrado un fragmento de cinta, que creemos correspondería al inicio de la guirnalda que aparece asociada a muchas aras monumentales ${ }^{20}$ (fig. 7).

${ }^{20} \mathrm{R}$. Turcan, "Les guirlandes dans I'Antiquite Classique» $J b A C$ 14, 1971 p. 113
Sobre la base de las medidas que se conservan hemos efectuado una reconstrucción aproximada de las dimensiones que podría tener el capitel; asi, tomando la nervadura central de la hoja de la segunda corona como eje del capitel, éste nos daría una medida de la base de 34 a $36 \mathrm{~cm}$, aproximadamente; por otra parte, por la estructura que conservan las dos coronas de acanto y por paralelos de estilo similar, suponemos que éstas ocuparían, aproximadamente, lo que corresponderia a la mitad de la altura total del capitel que, si asi fuera, sería de 46 a $48 \mathrm{~cm}$.

Al faltar toda la parte superior del capitel nos ha sido difícil encuadrarlo en un determinado momento cronológico; pero, a través del análisis detallado del fragmento que tenemos, nos atreveríamos a decir que, en líneas generales, mantiene las características de los capiteles de la península ibérica de época julio-claudia y flavia. Por este motivo, los paralelos que encontramos en el estilo deben ser tomadas con cierta reserva, pero nos recuerda algunos ejemplares de la península ibérica como los procedentes de la muralla de Barcelona, Córdoba ${ }^{21}$, Zaragoza y Clunia ${ }^{22}$ de esta misma cronología; también hemos encontrado similitudes, por el tipo de hoja y por la composición, con capiteles de los de-

\footnotetext{
${ }^{21}$ M. A. Gutiérrez Behemerid, Capiteles Romanos de la Peninsula lbérica, Valladolid 1992 p. $89, \mathrm{n}^{\circ} 291$ y n०2 294.

${ }^{22}$ A. Díaz Martos, Capiteles Corintios de Hispania, Madrid, 1985, p. $60, n^{\circ}$ B 32 y p. $53, n^{\circ}$ B 1.
} 

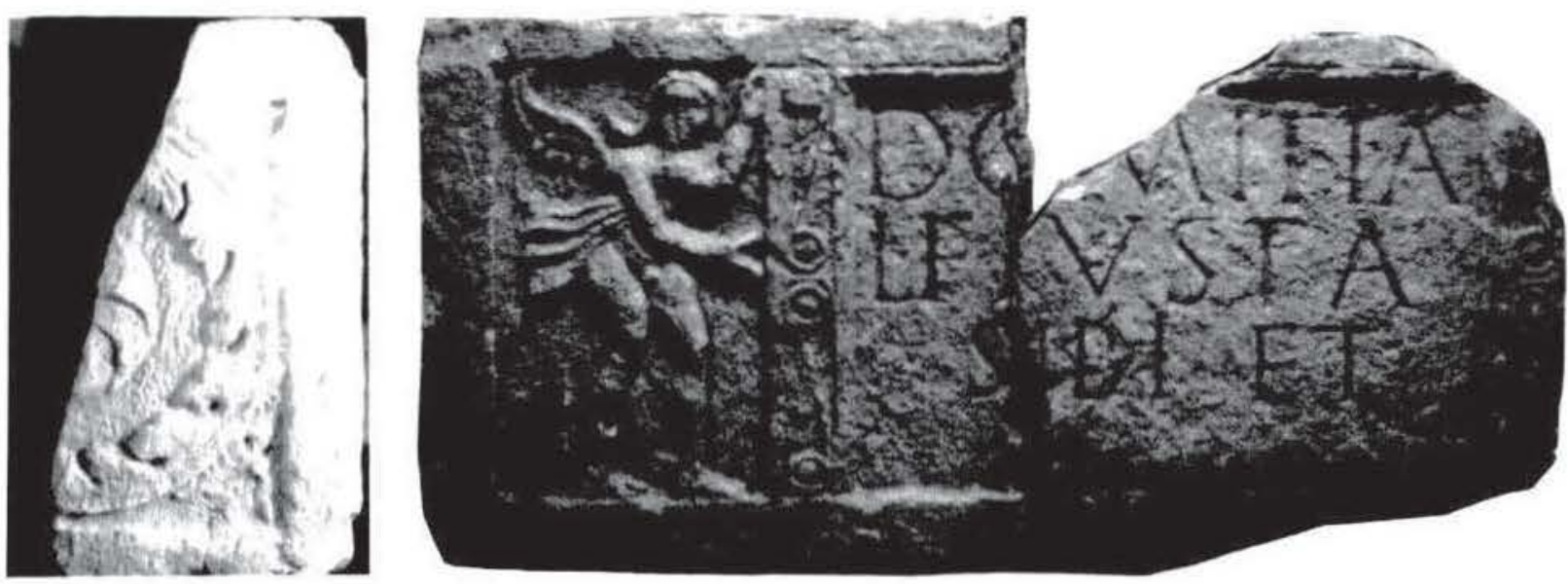

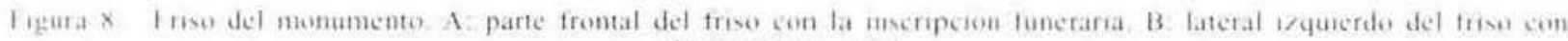
deceracion vegetal

nominados del segundo triunvirato, como los del arco de Bara de Tarragona:?

Fuera de la Peninsula vemos cierta semejanza con los capiteles hallados en el foro de Augusto y los de la Basilica lulia en Roma ${ }^{2}$, algunos ejemplares procedentes de Pola ${ }^{4}$, los tardo-augusteos del templo de Roma y Augusto. los del templo del ara redonda de Ostia ${ }^{-t}$ o los de la Maison Carré de Nimes? La cronologia de los paralelos que hemos aportado nos dirigen hacia modelos en uso a mediados del siglo id.C.

Son numerosos los paralelos que hemos encontrado por el tipo de hoja, pero el cauliculo vertical se aparta ligeramente de los capiteles de la cronologia que proponemos, siendo más propio de modelos mas tardios ${ }^{2 x}$, de fines del reinado de Adriano.

\section{El friso con la inscripcion funeraria}

A los pocos dias de iniciar los trabajos de excavación recuperamos, en el foso que existe en la cara norte de la planta, una parte fragmentada de la inscripción funeraria que tuvo el monumento. El soporte de la inscripcion. en la que afortunadamente se conserva el nombre completo de su propietaria, es un bloque de caliza blanca. muy blanda. de pro-

\footnotetext{
X Dupre. L'Are romá de Bera. Barcelona, 1994, p. 163.

W. D. Heilmeyer, Korinusche Normalkapitelle. Studien zur Gieschichte der rämixchen Architekturdekeratoon. Heidelberg. 1970. p. 184, lam 3, $n^{\prime \prime} 3$ y 4 y p. 185, lám. 13, n" ।

$\checkmark$ Scrimari. I Capitelli romani della lenecia Giulia. dell'stria. Padova 1952, p. I8.

th P. Pensabene, Scavi di Ostia. Vol.VII, Roma 1973, pp. 57. $58, n^{\prime \prime} 216,218$ y 219

"R. Amy y P. Ciros, "L a Mason Carrée de Nimes" XXXV' supplement à Gallia. Paris 1979. p. 49

${ }^{2}$ P. Pensabene, op. cit nota 26. p. 209
}

cedencia local. Este bloque esti fracturado e incompleto se ha perdido algún pequeño troso de su cara frontal y aproximadamente la mitad de su parte posterior. En alguna zona de la superficie del bloque. todavia se pueden apreciar restos de una fina capa de estuco blanco, que suponemos recubriria toda la inscripcion . El bloque que conservamos presenta decoracion en dos de sus caras (fig.8). En la frontal. delimitada por un listel, un eros con clamide al viento sujela con las manos una cartela, en la cual aparece un campo epigrafico con una parte de la inscripcion funcraria que tendria el monumento. El lateral isquierdo tiene como motivo decorativo un circulo de hojas de acanto con una flor central todo ello inscrito en un cuadrado flanqueado por un listel; de este motivo decorativo se conserva aproximadamente la mitad.

El campo epigráfico se enmarca por sus dos lados con sendos pares de volutas espiraliformes enfrentadas y con un fino listel que también aparece en la parte superior. Las medidas del campo epigrafico son $64 \mathrm{~cm}$ de ancho y $44 \mathrm{~cm}$ de alto. El epigrafe que se conserva dice lo siguiente (fig. 9):

Domitia

L(ucii) frilia) Iusta

sibi et

"Domitia Justa, hija de Lucio, para si y»

La inscripción está grabada con letra capital cuadrada, es regular y de buena factura, con trazos perfilados y ápices en todas las letras; existe interpunción en las dos abreviaturas existentes, detrás de la

204. S. Manzella, Mestiere di epigrafisła, Roma, 1987, p. 61 


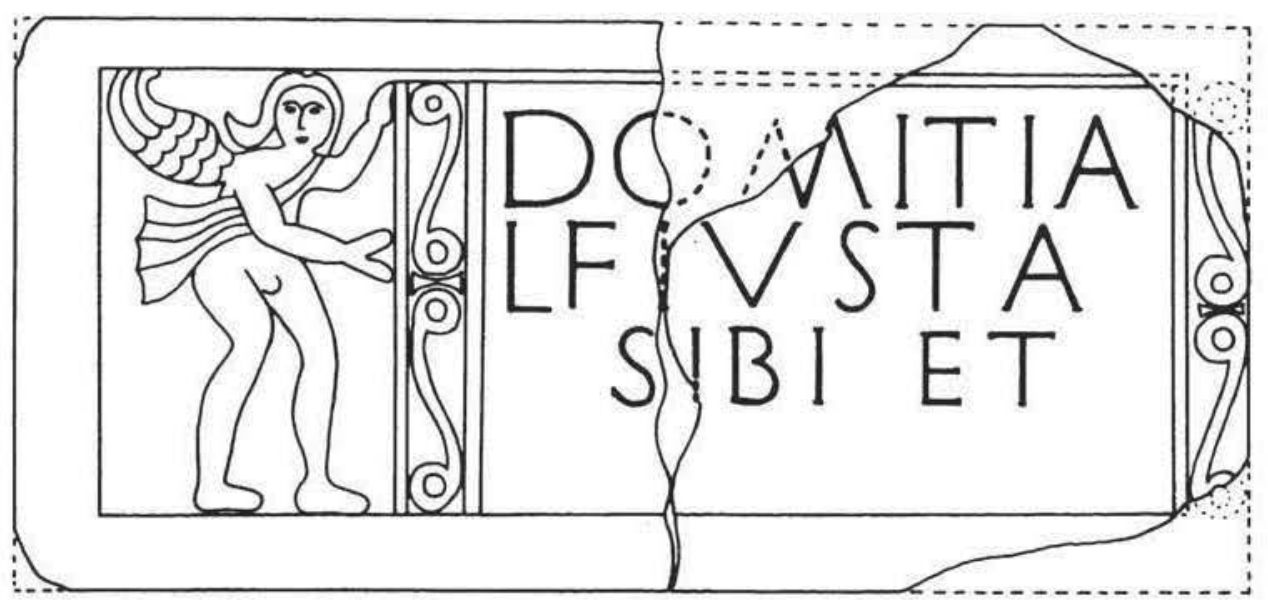

0

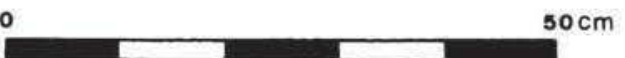

Figura 9.-Reconstrucción de la inscripcion funeraria.

L y de la F, respectivamente. Las letras de la primera y segunda línea miden $8,5 \mathrm{~cm}$ de alto y las de la tercera $7,5 \mathrm{~cm}$.

Un estudio más detallado de los caracteres epigráficos ${ }^{30}$ aporta datos sobre la cronología de esta inscripción; la " $\mathrm{D}$ " y la "V», presentan la misma medida de ancho que de alto, la "O $\mathrm{O}$ " es redonda y la «E» tiene las líneas transversales de la misma medida. Además de ello, la mención en nominativo, los rasgos paleográficos, la ausencia de la fórmula D M, tan extendida a partir del siglo II d.C., o la presencia de la filiación, sugieren una cronología del siglo id.C.

La estructura de la inscripción permite afirmar que continuaría por su parte derecha, con uno o varios campos epigráficos en los que se desarrollarían los nombres de las restantes personas para las que, presumiblemente, también fue dispuesto el monumento y, al menos, otro erote, enfrentado al que conservamos, cerraria la inscripción del monumento por su parte derecha, ocupando el conjunto todo el ancho de la fachada principal. Esta circustancia fue bastante usual y se conocen construcciones funerarias en las que un solo edificio sirvió para albergar a varios miembros de la misma familia; las encontramos en Hispania, por ejemplo, en el monumento de los Atilii de Sádaba ${ }^{31}$, en el de los Sergii

${ }^{30} \mathrm{~J}$. S. y A. E. Gordon, Contributions to the Palaeography of Latin Inscriptions, Berkeley-Los Angeles, 1957; I. S. Manzella, op. cit. nota 29.

" J. Menéndez Pidal, "El mausoleo de los Atilios». AEspA 43, 1970, pp. 89-112. de Sagunto ${ }^{32}$, en el de los Domitii de la Iglesuela del $\mathrm{Cid}^{33} \mathrm{o}$ en el de los Fabii de Chiprana ${ }^{34}$.

La decoración que presenta este bloque, en lineas generales, no manifiesta una factura muy elaborada, como se ha podido ver en las otras piezas decoradas, lo que contrasta con la regularidad y buen trazado de los caracteres epigráficos.

Nuestro erote, a pesar de ser parte del motivo decorativo principal que tendría la inscripción, presenta unos rasgos desproporcionados que reflejan una elaboración poco cuidada. En un análisis formal más minucioso se aprecian bien las características que acentúan más esta sensación de descuido; así, las manos y el cabello sólamente están esbozados, la extremidad del ala aparece totalmente curvada y, al igual que la cabeza, en contacto con el listel superior, dando una sensación de falta de espacio y de estar comprimida la figura; suponemos que la onda tan marcada del cabello y la clámide al viento, se deben al deseo del artesano de dar un sentido de movimiento a la figura, intentándola presentar en actitud de vuelo como si una ráfaga de aire incidiera de lleno sobre ella o como si deseara elevarse. La tosquedad del grabado de la figura, unido a la erosión que presenta, no permiten apreciar de-

\footnotetext{
32 J. L. Jiménez Salvador, "El monumento funerario de los Sergii en Sagunto". Homenatge A. Chabret. 1888-1988, Valencia, 1989, pp. 207-220.

${ }^{33} \mathrm{~F}$. Arasa y Gil, «El monumento de la ermita de la Virgen del Cid (La Iglesuela del Cid, Teruel)". Boletin del Museo de Zaragoza 6, 1987, pp. 141-179.

${ }^{34} \mathrm{~J}$. Lostal, Arqueologia del Aragón romano, Zaragoza, 1980, pp. 172-174.
} 
talles de su elaboración, aunque todavia son bien visibles las pupilas grabadas, con dos agujeros redondos, mediante el uso del trépano. La desproporción de la figura, el tipo de material calizo sobre el que está grabada y la técnica de trabajo empleada en su elaboración nos recuerda las figuras de los relieves funerarios aparecidos en Mengibar ${ }^{35}$; también se aprecian similitudes, por los motivos y la forma de labra, con determinados materiales procedentes de la Narbonense ${ }^{36}$.

La figura de eros, como consecuencia de los múltiples caracteres que posee, tiene en el mundo romano una iconografia amplia y variada ${ }^{37}$. Uno de los casos más atestiguados es el eros funerario, que aparece representado en diferentes actitudes, decorando urnas, sarcófagos y monumentos funerarios. Son numerosas las representaciones en las que aparecen erotes en actitud de vuelo trasportando la figura del difunto dentro de un clípeo, actuando como agente de ascensión e intercesor entre el difunto y el más allá ${ }^{38}$. Varios ejemplos ilustran estas funciones, $\mathrm{y}$ asi lo encontramos en el relieve del arco de Portogallo o en la columna de Antonino Pio de Roma ${ }^{39}$, donde el difunto aparece transportado por estos personajes alados; este mismo significado creemos que tienen las representaciones en las que, como en nuestro caso, el eros transporta o mantiene la cartela donde aparece la inscripción funeraria que, de forma escrita, representa la identidad del difunto.

Los paralelos más próx imos para nuestra inscripción, por lo que se refiere a la disposición de las figuras y a las medidas, los hemos encontrado en la Galia. Procedentes de Lión se conservan dos bloques funerarios de proporciones similares al nuestro que, por la decoración que presentan en dos de sus caras, debieron formar parte de las esquinas de sendos monumentos funerarios. En la cara frontal de ambos, un erote mantiene con las manos parte de una cartela con inscripción ${ }^{40}$; en los dos casos, se ha perdido el bloque que continuaría con el resto de la inscripción funeraria, pero suponemos que ésta se cerraría con otro eros simétrico al que aparece en el bloque conservado. Procedente de Heidenburg (Galia Germánica) tenemos otro bloque completo con

\footnotetext{
${ }^{35}$ L. Baena del Alcázar, "Relieves romanos de Mengibar (Jaén)", Italica 17, 1984, p. 145.

${ }^{36} \mathrm{~J}$. Hatt, La Tombe gallo-romaine, Paris, 1951, pp. 133-134.

${ }^{37} \mathrm{Ch}$. Daremberg y E. Saglio, Dictionnaire des antiquités greques et romaines d'apres les textes et les monuments, París, 1877 1919, vol. s. v. Eros p. 1595.

${ }^{38} \mathrm{R}$. Stuveras, Le putto dans I'art romain, Bruselas, 1969, p. 46.

${ }^{39} \mathrm{~J}$. Arce, Funus Imperatorum, Madrid, 1987, pp. 137 y 149.

${ }^{40}$ E. Esperandieu, Recueil des bas-reliefs de la Gaule romaine, París 1907 y ss., tomo IV, $n^{\circ} .3112$ y $\mathrm{n}^{\circ} .3530$.
}

este mismo motivo iconográfico en la parte frontal y también decorado en los laterales ${ }^{41}$. Estos ejemplos, por sus dimensiones, formarian parte de monumentos funerarios cuya tipologia concreta desconocemos, pero que mantendrían la misma disposición de la del bloque con inscripción funeraria que estamos estudiando. En Germania Inferior lo hemos encontrado asociado a un cipo monumental, el monumento funerario de $C$. Albinius Asper, de Niimagen ${ }^{42}$.

Al margen de estos paralelos, encontramos también un abundante grupo de inscripciones de diversa indole que, sin tener decoración en los laterales, presentan este mismo motivo iconográfico. La mayor parte de estas inscripciones, recuperadas fuera de su contexto original, proceden de Galia Germánica ${ }^{43}$, pero otros ejemplos han sido hallados en Lión ${ }^{44}$ y Bélgica ${ }^{45}$.

La dispersión de estas inscripciones, que mantendrian el mismo esquema que la nuestra, coincide con zonas bien romanizadas donde las aras están muy documentadas; esto nos hace pensar en la probabilidad de que algunos de estos bloques hubiesen pertenecido a altares, más o menos monumentales, ya que en alguno de los casos citados, por la inscripción sabemos que pertenecieron a comerciantes y militares ${ }^{46}$, a cuya clase social va asociado este tipo de monumentos ${ }^{47}$. Además, en la misma zona geográfica documentamos el mismo diseño aplicado, como única decoración, en la parte frontal de sarcófagos ${ }^{48}$, con estilo muy similar al de los bloques pertenecientes a monumentos ${ }^{49}$. También en

\footnotetext{
${ }^{41} \mathrm{lbm}$, tomo VIII, $\mathrm{n}^{\circ} .6103$.

${ }^{42}$ W. v. Massow, Die Grabmäler von Neumagen, Berlin, 1932, p. 42 .

${ }^{43}$ E. Esperandieu, op. cit. nota 40 , tomo VII, $n^{\circ} .5 .697$, tomo VIII, 6.212, tomo IX, 6.361 y 6.564 .

${ }^{44} \mathrm{Ibm}$, tomo IV, $\mathrm{n}^{\circ}, 3.579$.

${ }^{45} \mathrm{Ibm}$, tomo V, $\mathrm{n}^{\circ} .4 .000$ y 4.224 , tomo VI, $\mathrm{n}^{\circ} 4.596,4.714$ y 4.808 .

4h $\mathrm{Ibm}$, el $\mathrm{n}^{\circ} .6361$ del tomo IX y el $\mathrm{n}^{\circ} 728$ de Recueil Géneral des bas-relieves, statues et bustes de la Germanie romaine, $\mathrm{Pa}$ ris, 1931 ambos pertenecieron a monumentos de dos personajes de la clase militar, el $\mathrm{n}^{\circ} 6564$, también del tomo IX, a un mercader de trigo.

${ }^{47} \mathrm{~A}$. Candeloro, «ll problema del fregio dorico nei monumenti funerari d'Abruzzon, Papers in Italian Archaeology 4, 1985.

${ }^{48}$ E. Esperandieu, op. cit. nota 40 , procedente de la Narbonense, tomo I, $n^{\circ} 132,174,308$ y el 498 muy similar al nuestro también con guirnaldas en los laterales; procedente de Aquitania, tomo II, $n^{\circ}$ 1402; procedentes de Galia Germánica, tomo VII, $n^{\circ} .5631$, tomo VIII, $n^{\circ} 6437$ y tomo IX, $n^{\circ} 6576$; procedente de Lión tomo III, $\mathrm{n}^{\circ} 1774$ y procedente de Bélgica tomo VI. $\mathrm{n}^{\circ}$ 4490. A. Spieb, "Studien zuden Römischen Reliefsarkophagen aus den Provinzen Germania Inferior und Superior, Belgica und Raetian, K. J. F. 21, 1988, pp. 253-324.

${ }_{49} \mathrm{Ibm}$, véase la similitud que presentan el $\mathrm{n}^{\circ} 3112 \mathrm{del}$ tomo IV, perteneciente a un monumento funerario y el $n^{\circ} 1774$ del tomo III de un sarcófago, ambos procedentes de la zona de Lión.
} 
un sarcofago procedente de York, en Britania, se reproduce este mismo motivo iconográfico ${ }^{60}$.

Reproducimos el perteneciente a un sarcófago encontrado en Lión. que consideramos el más similar al bloque de L a Calerilla, porque tiene, de la misma manera que nuestra inscripción. las volutas espiraliformes enmarcando la cartela ${ }^{4}$ (fig. 10).

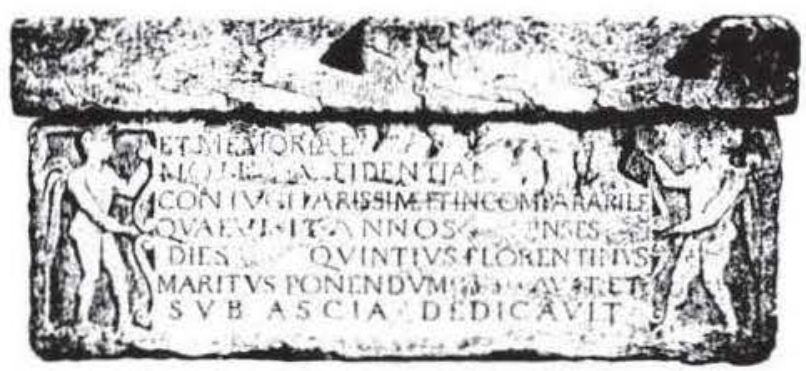

Figura 10. Sarcólage procedente de Lion tomado de f sperandieu (op. cit nota 49), tomo III, $\mathrm{n}^{\prime 2} 2155$

En la Galia parece ser que las cartelas epigraficas sustentadas por erotes fueron bastante utilizadas en monumentos funerarios, de donde suponemos se tomarian como modelo para sarcófagos y otras construcciones funerarias menos costosas. Esto mismo parece que ocurre con otros motivos iconográficos como el thiasos marino, que aparece en monumentos funerarios del siglo i y en sarcófagos del siglo $\|^{52}$ o con escenas presentes en la serie de monumentos de Niimagen, que llegan a constituir motivos frecuentes en sarcófagos de temas cristianos ${ }^{4}$,

En Italia, este motivo iconográfico se encuentra en la tumba de Trajano, en la parte superior de la base de la columna, sobre la puerta de la fachada principal, donde dos erotes aparecen representados con las alas extendidas, trasportando entre sus manos la inscripción funeraria. En la misma disposición lo vemos en unos sarcófagos, procedentes de Aquileia y Venecia, que imitan edificios funerarios con pilastras en las esquinas $y$, ocupando todo un frente, dos erotes manteniendo la inscripción ${ }^{54}$. Un grupo de sarcófagos, procedentes de Roma, fecha307

"G. Koch y H. Sichtermann, Römische Sarkophage, 1982, p.

"Esperandicu, op, cit. nota 40, tomo III, n" 2.155.

"7. Beltrán Fortes, "Mausoleos romanos en forma de altar del sur de la Peninsula Ibérican, AEsp.4 63, 1990, pp. 183 ss..

"j. Beltrán Fortes, «El sarcófago de tema pagano en la Béticas. Actas de la reunion sobre escultura romana en Hispania, Madrid, 1993, pp. 83-84.

${ }^{*} \mathrm{H}$. Gabelmann, Die Werkstattgruppen der oberitalischer Sarkophage. 1973, pp. 46-47. dos en los siglos $\|-1\| "$ " manticne una composicion similar.

En la peninsula iberica. no hemos encontrado ningún paralelo para el motivo decorativo de nuesIra inscripcion. pero hay noticias de que en un monumento funerario de Clunia. la inscripción vendria Manqueada con dos genos alados " y que este mismo motive se representaria tambien en un sarcofago. procedente de Aleala de Guadara" en la actualidad en paradero desconocido.

En cuanto a las volutas espiraliformes que enmarcan la cartela de nuestra inscripcion, aparecen asociadas a la decoración de urnas ". sarcofagos" $y$ aras funerarias ${ }^{t+1}$, ocupando diferentes lugares. En nuestro entorno más inmediato. las encontramos en una inscripcion de Sagunto ${ }^{61}$. dos de Almenara ${ }^{62}$. una de Begis ${ }^{62}$ y en otra inscripción funcraria proeedente de la necrópolis del Pelao en Jorquera (A)bacete) ${ }^{\text {th }}$. Esta última. es la que más interés presenta. pues por la proximidad geografica, similitud estilistica, cronológica y paleográfica nos hace pensar en que las dos procedieran de un mismo taller (fig.11).

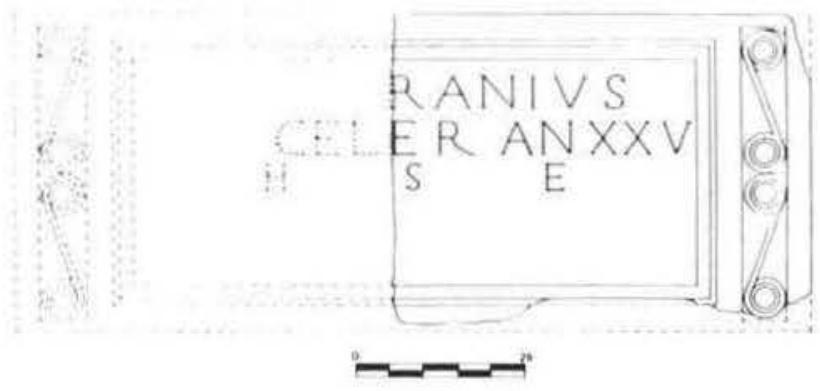

ligara 11. Inseripeton procedente de Jorquera (Albacete) tomada de Abascal (11) cit nota 76 ), $n^{\circ}$ is.

" M. Sapelli y M. Bertinetli. Museo Nacionale Romano. I Sarcofagi. Parte 1I. Roma, 1984, de Sapelli n' 225, 229, 234 y de Bertinetti $n^{*} 226,230,236$ y 247

"6 $\mathrm{M}$. Cancela. "Elementos decorativos de la arquitectura funeraria de la Tarraconense Oriental», Actas de la reunion so. bee excultura romana en Hispania. Madrid, 1993. p. 250.

1. Beltran Fortes, op. cit, nota 53, pp. $78-79$

"F. Cumont. Catalogue des sculptures et inscriptions anfiques. Bruselas, 1898, $\mathrm{n}^{\circ} 89$

${ }^{44}$ Esperandieu, op. cit. nota 40, tomo III, véase el sarcófigo n" 2.155 .

of L. Baena del Aleazar, "El ara romana del Museo Arqueológico Municipal de Antequeran, Arqueologia de Andalucia Oriental: siete estudios. Málaga, 1981, p. 83. fig. 7.

") F. Beltrán Lloris, Epigrafia latina de Sagumtum y su territorium, Valencia, 1980, $\mathrm{n}^{\circ} 113, \mathrm{p}, 119$, Iam. XXXVIII.

${ }^{2} 2$ J. Corell, Boletin de la Sociedad Castellonense de Cultura. tomo LXV1-2, $1989 \mathrm{n}^{\circ} 8$ y II, pp. 201.202

6. F. Arasa i Gil, La romanización del Alto Palancia seguin la epigrafia, Segorbe, 1992, p. 71, n 5, lam. III.

a J. M. Abascal, Inscripciones romanas de la provincia de Albacete, Albacete, 1990. $n^{\circ}$ 18, p. 41 
Las volutas espiraliformes tambien las hemos encontrado en el monumento funcrario de los Domini".". reutilisado para la construecion de la ermita de la Virgen del (id en la Iglesuela del Cid (Teruel). asociadas a una inscripcion que debio pertenecer a un ara monumental. a juzgar por la presencia de un pulvinus. que se encuentra encajado en las paredes de este santuario.

La presencia de motivos vegetales decorando monumentos funerarios, como en nuestro caso, es una tradicion que se origino en epoca griega arcaica. se mantuvo en epoca romano-republicana y alcan so su maximo desarrollo en epoca julio-claudia y flavia ${ }^{(t)}$. Su vinculacion con la arquitectura funeraria es tal que Janon. en su trabajo sobre la decoración arquitectonica de Narbona ", da un caracter funerario a numerosos bloques de piedra decorados con medallones y recuperados sin contex to arqueológico.

El motivo vegetal de nuestra inscripción lo constituye una flor de seis petalos radiales con los extremos apuntados en sentido giratorio, todos en la misma direccion. Este tipo de flor tiene su posible origen en los propileos de la zona norte de Epidauro y fue el motivo vegetal más utilizado para los florones del Ara Pacis de Augusto ${ }^{\circ .}$, a partir de donde probablemente se difundió.

Este tipo de flor, denominado «a girandola», con pequè̃as variaciones, suele estar asociada a monumentos que desarrollan frisos dóricos ${ }^{6 *}$; asi, la encontramos en Sarsina, en el friso y en la cornisa de la tumba de Asfionius Rufus y en el mausoleo de Ohulacus ${ }^{70}$ : en Ostia se documenta en el monumento de Porta Marina ' $y$ en Pompeya en la tumba norte 6 de la necropolis de la Puerta de Herculano?2.

En la peninsula ibérica hemos visto representado este motivo en varias estelas funerarias procedentes de la Meseta, guardando el motivo vegetal de nuestra inseripción una gran similitud con el que presenta una estela procedente de Xinzo de Limia ${ }^{73}$.

4. Arasa, 1987: op. cil nota 33. p. 161

6. Gauron. "Les cippes funeraires Giallo-Romains à decor de rinceaux de Nimes et sa région”. Gallia, 41, 1983 pp. 59-61.

- M. Janon, le decor architectenique de Narbonne. Narbonil, 1984. pp. 12 y 13.

${ }^{n} \mathrm{llom}, \mathrm{pp}, 25-29$

"M.Torelli, "Monumenti funerari romani con fregio dorico". Dial. Arch., II, 1. 1968, p. 38.

"S. Aurigenma. Il monumenti della necropoli romana di Sarsina. Roma. 1963. pp. 30-31 y 74-75.

M. F. Squarciapino, Scavi di Ostia, III, Roma 1958. pp. $181-190$.

V. Kockel. Die Grabhauten vor dem Herkulaner Tor in Pompeji, Roma, 1982, lám. 43-47

73. A. Abásolo Alvare/, "Las estelas decoradas de la Mesetas, Actas de la reunion sobre escultura romana en Hispania. Madrid, 1993, p. 186.
Lna comnisa de oras r dardes

En la fosa colmatada del lado norte, donde se encontraba la inscripcion funcraria. recuperamos cuatro fragmentos de piedra ealiza que pertenecieron a una cornisa de ovas y dardos (fig. 12)

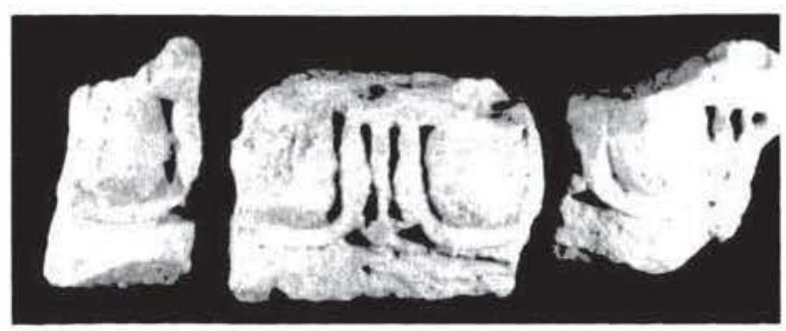

Figura 12. Fragmentos de la moldura de onas y dardos

Estas piezas se encuentran talladas sobre unos pequeños bloques, que estan fracturados, y para ello se utilizó la caliza gris que caracteriza al monumento. Las ovas se presentan muy redondeadas dentro de una concha que las envuelve y entre ellas se encuentran unos dardos que terminan en forma de rombo. La factura de estas piezas es, en general, algo tosca e irregular, como ocurre con los otros motivos decorativos, pero se consigue un buen efecto, porque mediante una talla profunda se consiguen destacar las sombras y el volumen.

Desconocemos el emplazamiento original de esta moldura, pero suponemos que se situaria coronando el friso del monumento, en la hilada inferior de la cornisa que adornaria la parte superior del edificio. Pocos datos nos pueden aportar estos pequeños fragmentos, pero la terminación de los dardos en forma de rombo nos recuerda las molduras augusteas $^{74}$.

\section{La moldura superior}

En el transcurso de la excavación recuperamos dos fragmentos de una moldura, con un perfil diferente al que hemos identificado como perteneciente a la base del monumento, lo que nos hizo suponer que, al igual que en otras construcciones de esta tipologia, una moldura adornaría la parte superior del edificio sobre la que descansarian los dos pulvini del altar (fig. 13).

El esquema que presentan estos fragmentos es similar al de la base, pero ligeramente más recargado. El perfil que se conserva del fragmento más completo es el siguiente: caveto, filete, faja, óvalo y fi-

"P. Chiner, La decoración arquitectonica en Saguntum, Valencia, 1990, p. 121. 


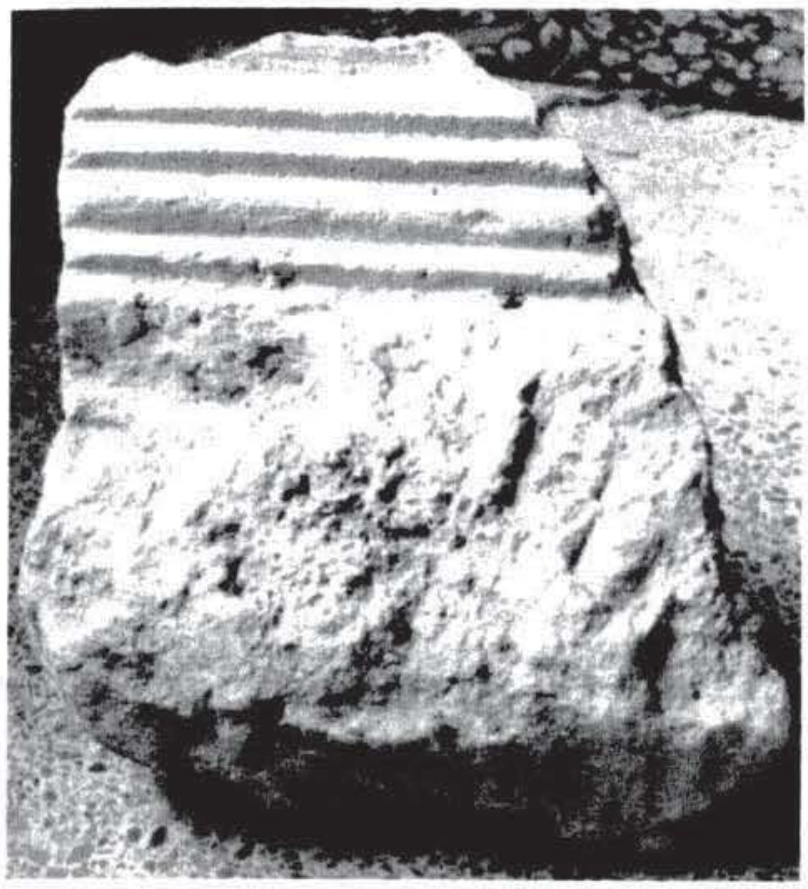

Figua 13 Fragmeno de la cormsa molduada superior ef motiumento.

lete. Al estar fracturada la parte superior, suponemos que este esquema conservado se repetiria de forma simetrica hacia arriba, quedando toda la moldura, de arriba abajo, de la forma siguiente: filete. ovalo, faja, filete, caveto, filete, faja, ovalo y filete (fig. 14).

De esta manera, las molduras superior e inferior del monumento tendrian una forma similar. con la única diferencia de que la moldura superior presentaria las dos fajas que no existen en el perfil de la moldura inferior.

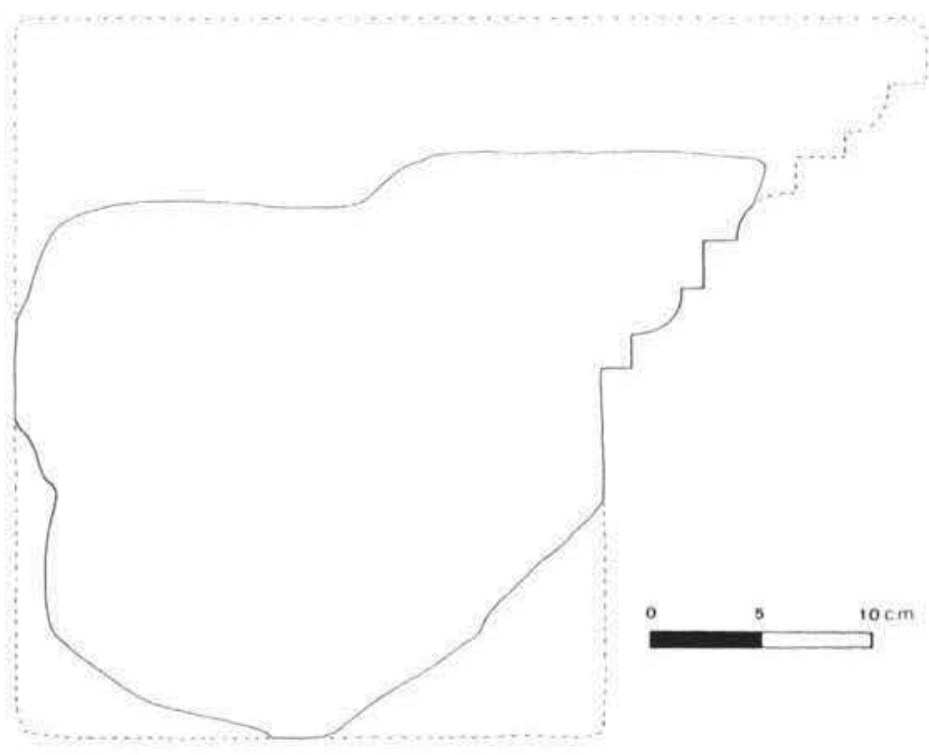

Figura 14. Reconstruceion ideal de la moldura superior.

\section{El pulvimus}

En el lado este de la planta del monumento. y desplazado por el arado, recuperamos un fragmento del lateral y parte frontal de uno de los dos pulvini que remataria el monumento: este pequeño fragmento. ha sido la piesa fundamental para poder adscribir el monumento a una tipologia concreta

E) fragmento que conservamos se labró con el mismo tipo de piedra calisa gris que el resto de las utilizadas en el al/ado del edificio. Las medidas que se conservan son: $23 \mathrm{~cm}$ de longitud y $32 \mathrm{~cm}$ de altura. La parte del cuerpo esta decorada por bandas de hojas lanceoladas gruesas con nervadura central y borde bien perfilado (fig 15). Se conservan dos de

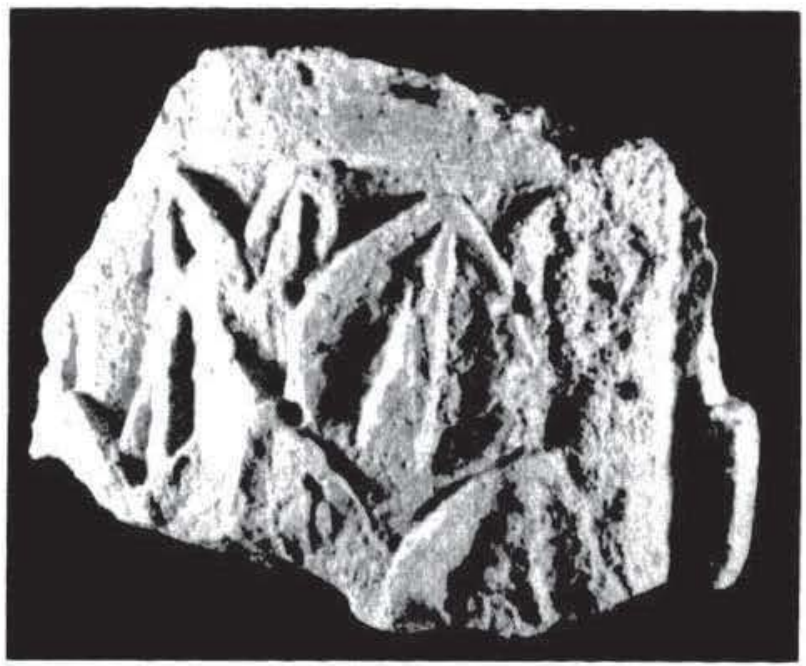

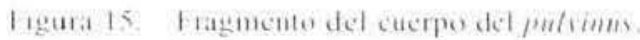

estas bandas: de las hojas de la más extrema asoman las puntas de unas hojitas intermedias mas pequeñas, que terminan en el inicio de la moldura de la parte frontal. Por la parte inferior del fragmento conservado parece identificarse el inicio del listel de base que apoyaria sobre el monumento. La parte frontal presenta un segmento de circunferencia, perteneciente a una moldura de angulo que delimita las extremidades apuntadas de lo que parecen ser varios pétalos de un motivo vegetal (fig. 16).

Con el pequeño fragmento conservado, seria muy arriesgado intentar una reconstrucción total del pulvinus, pero suponemos que su cuerpo vendria decorado con la superposición, de forma alterna, de hojas similares a las definidas. El diámetro del pulvinus lo hemos podido calcular por el segmento de circunferencia de la moldura de ángulo que conserva en su parte frontal, lo que daria una medida aproximada de $45 \mathrm{~cm}$. 


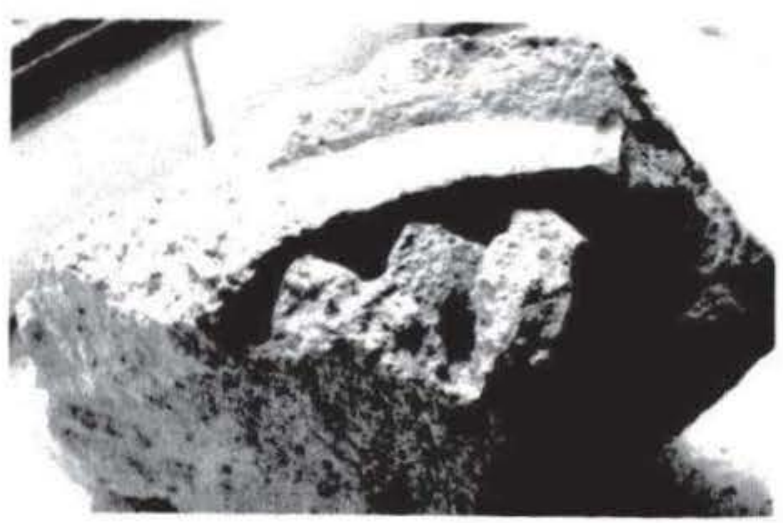

Hegra to firgmente de La parte trontal del pulsmus

Por los restos que quedan del motivo legetal de la cara frontal y de la moldura que lo enmarca, pensamos que el pulvinus podria estar decorado con una roseta. de un estilo similar a la que posee el pulvinus perteneciente al cenotafio de Agripa ${ }^{* 6}$. que tambien presenta el mismo tipo de moldura. Suponemos, pues, que estarian exentos, tendrian un perfil rectilineo. con un balteus en su parte media. sin los alargamientos laterales que caracterizan a algunas piezas de Barcelona o de Jaén ".Pulvinti similares al nuestro podrian ser dos del Musco Nacional Romano. de los que uno tience el mismo tipo de moldura y de flor que pensamos podria tener el nuestro y otro de Pompeya. perteneciente a la tumba norte III de la necropolis de la puerta de Herculano ${ }^{2 x}$.

Al no existir. hasta la actualidad, un estudio completo de estos materiales es dificil poder precisar por el estilo su datacion, pero parece ser que los puhrimi de perfil rectilineo, tipicos de las piezas del Lacio y de la Campania, son cronologicamente anteriores a los de perfil curvo, bien documentados en Sarsina y Aquileia ${ }^{24}$.

Los pulvini que conocemos en la peninsula ibérica, aparecen decorados en el frente con motivos vegetales. con la cara del difunto o con la cabeza de Gorgona. lo que parece más común a partir de época flavia ${ }^{* 1}$. De todos ellos, el más similar al nuestro es un fragmento que procede de Tucci (Jaén) ${ }^{\mathrm{N}}$; este

\footnotetext{
1. I a Rocet, La riva a mezaltina. Roma, 1454, pp. 87-106

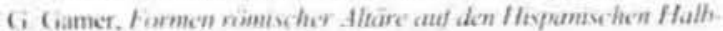
imsel. Mainz, $19 \times 9$

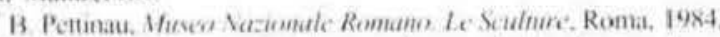
1.71. pp 438 y $4 \times 6$, en este ulimo $x$ da una relacion de ejemplares similares at nuestro aparecidos en Italia. para los ques se propene una cronologea julionclaudia.

V. Kockel, of cit, nota 72, lam. 35

"F. I a Rocca, op cit nota 75, p. 93.

1. Beltran, op cit nota 53, p. 191

Hom. p. 215, fig. 17
}

pulvmas, presenta una flor wa girandolam parecida a la que decora el lateral de nuestra inscripcion. que tambien aparece en el frente de los pulvini de una pequena arat procedente de Lvora ". con las hojas del cuerpo muy similares a las que decoran el nuestro

\section{ARFCONSTRI CCION DEL MONUMENTO}

Fl deterioro en que se encontraba el monumento funerario de Domita lasta. en el momento de la excavacion, hace que las reconstrucciones que ahora proponemos deban ser tomadas como meros ensayos aproximativos de lo que este monumento pudo haber sido. conscientes de que con los escasos elementos que han permanecido in situ y los pocos restos decorados con los que contamos. solo podemos esbozar lo que pudo haber sido su forma original.

De todos los elementos que manejamos para la reconstrucción del monumento. los únicos que han conservado alguna medida integra. que pueda aproximarnos a sus dimensiones, son el lado noreste de la plataforma de cimentacion. el bloque perteneciente al friso donde aparece la inscripcion funcraria y los escalones del focalo, sobre los que se conserva la marea de apoyo de un bloque superior: el resto de las medidas las hemos calculado con los fragmentos que se han conservado. A partir de estas medidas y con los elementos decorativos que tenemos, hemos hecho una reconstrucción que se ajuste a la forma y a las proporciones de algún monumento conocido de esta tipologia.

Para reconstruir la medida de la fachada principal partimos de la hipotesis de que existirian otros difuntos para los que se dispuso el monumento. como parece deducirse de la inscripción que se ha conservado: de esta manera. suponemos que esta, continuaria. al menos, con otro bloque similar al conservado con la parte que falta de la inscripcion y que otro erote cerraria el campo epigrafico con la disposicion que ya hemos visto. Suponiendo que asi fuera. la dimensión de la fachada por este lado seria $2,36 \mathrm{~m}$, medida ésta que corresponde a la existencia de otro bloque similar al que se conserva: la anchura total del monumento por su base seria de $3.56 \mathrm{~m}$. deducida a partir de la suma del ancho del friso $(2.36$ $\mathrm{m})$. del ancho de la moldura $(10 \mathrm{~cm}$ at cada lado) y de los dos escalones $(25 \mathrm{~cm}$ cada uno y dos escalones a cada lado) ${ }^{\mathrm{k}}$ : esta medida, nos parece reduci-

\footnotetext{
G. Camer. op cat nota 76, p. 173, lam 92

I1 primer escalon es seguro que tenia $25 \mathrm{~cm}$ de ancho pero se desconoce la medida exacta del segundo, aunque suponemos que podria ser la misma.
} 
da para los $5,15 \mathrm{~m}$ de lado que se conserva de la plataforma de mampostería de la cimentación y asi pensamos que el monumento tendria en la fachada principal y su opuesta unas dimensiones superiores.

Existen dos posibles soluciones para que la fachada del edificio alcanzara unas medidas más acordes con las de la base de cimentación que tenemos por este lado. Por una parte, la existencia de otro campo epigráfico, de igual medida al conservado, entre el bloque que tenemos y el simétrico, delimitado por otro par de volutas espiraliformes y por el pequeño listel de $3 \mathrm{~mm}$ que las acompaña, de esta manera, quedaría con la disposición que se ve en la (fig.17), alcanzando la fachada del edificio una longitud por este lado de $3,25 \mathrm{~m}$ a lo que sumariamos el espacio que ocuparian los dos escalones del zócalo de $25 \mathrm{~cm}$ cada uno y la moldura de la base. llegando a una longitud total de $4,43 \mathrm{~m}$; proponemos esta solución sabiendo que existen epigrafes para varios difuntos delimitados por varios campos epigráficos ${ }^{x 4}$, si bien no hemos encontrado ningún paralelo en que aparezcan enmarcados con erotes.

La otra solución que proponemos seria que la inscripción que se ha conservado, continuase con otro erote de idénticas caracteristicas al que presenta el friso en la parte izquierda con su pequeño listel, de modo que todo el conjunto midiera $1,54 \mathrm{~m}$ y que a continuación se repitiera otro campo epigráfico con erotes similares, donde continuara la inscripción, con el nombre de otro difunto (fig.18); esta solución permitiria dejar un espacio entre los dos erotes centrales, que podria presentar cualquier motivo decorativo y se podria adaptar, junto con los escalones y la moldura de la base, a las medidas exactas de la planta.

* G. Pereira, "Inscripciones latinas del Museo de Prehistoria de Valencias $A P L$ XV. 1978, véase un caso similar en la p. 257. donde el contenido de la inscripción aparece dividido en tres campos epigráficos.

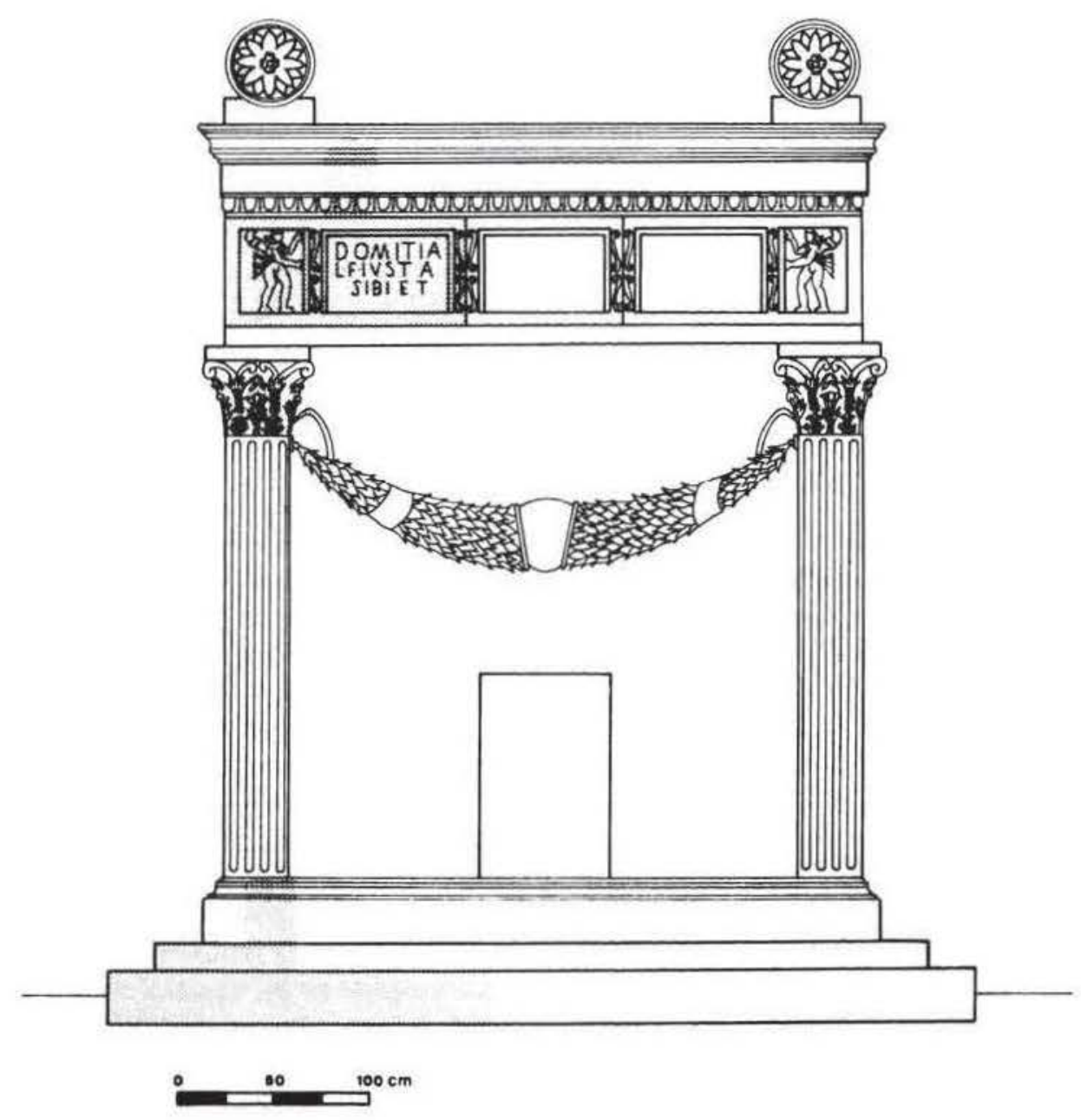

Figura 17.-Reconstrucción del altar de La Calerilla con tres campos epigráficos. La parte tramada corresponde a las partes conservadas. 


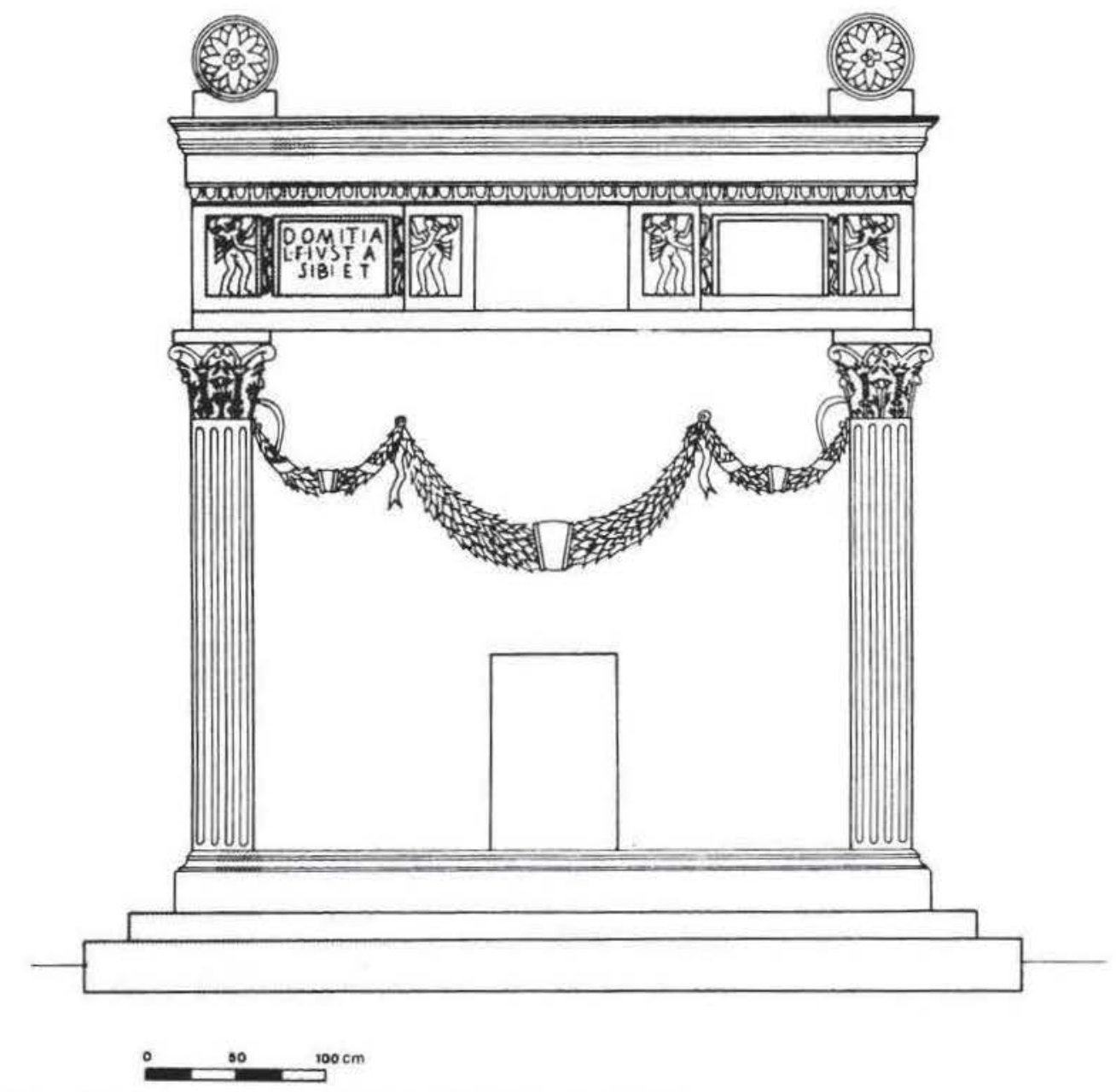

Figura 18. - Reconstrucción del altar de La Calerilla con dos inscripciones delimitadas por erotes. La parte tramada corresponde a las partes conservadas.

En cuanto a la propuesta de reconstrucción del monumento por sus lados más cortos, hemos tenido la dificultad de encontrar estos laterales incompletos. Para la reconstrucción de las medidas de esta parte del friso nos hemos basado en el motivo vegetal que aparece en el lado opuesto de la inscripción y que, por el lugar que se recuperó, estaría situado en el ángulo noreste del monumento. Pensamos, que a partir de este motivo conservado, de $58 \mathrm{~cm}$, se podrian repetir otros motivos decorativos de la misma medida, con una decoración vegetal similar, páteras, bucráneos o algún motivo en la tradición de los frisos dóricos, como es éste que tenemos de la flor "a girandola" (fig. 19).

Según la reconstrucción propuesta del zócalo por los lados más cortos, con los dos escalones que medirían $20 \mathrm{~cm}$ cada uno y los $10 \mathrm{~cm}$ de la moldura inferior, quedaría un espacio máximo para cinco de estos motivos vegetales que, si así fuera, daría una medida de 2' $90 \mathrm{~m}$, y para todo el edificio de $3,90 \mathrm{~m}$; esta medida se ajustaria a la reconstrucción que proponemos para la plataforma de cimentación por estos lados.

Para calcular la altura que podria tener el edificio, hemos tenido más dificultad, ya que las únicas medidas integras relacionadas con la altura son la del bloque de la inscripción, que nosotros situamos en el friso, y la de los dos escalones del zócalo; hemos tenido en cuenta también, las diferentes medidas que hemos calculado con los fragmentos del pulvinus, de la cornisa superior e inferior, de la moldura de ovas y dardos y del capitel; por otra parte, contamos con la reconstrucción que hemos efectuado de los lados del edificio. Con todos estos elementos hemos buscado un altar que se ajustara a estas proporciones.

El edificio más similar que hemos encontrado con el altar de La Calerilla de Hortunas es la tumba 


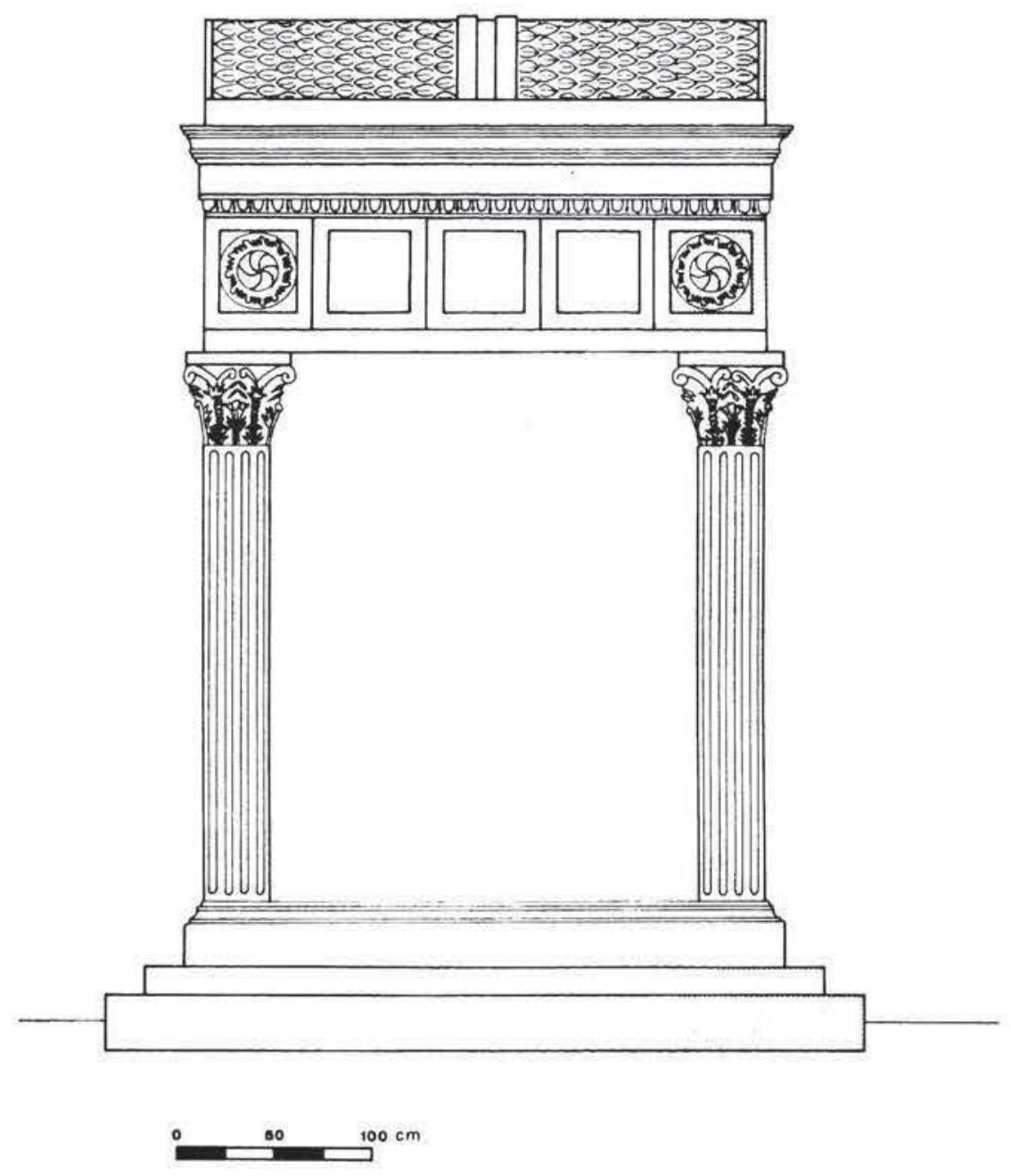

Figura 19.- Reconstrucción del altar de La Calerilla por su lateral izquierdo. La parte tramada corresponde a las partes conservadas.

de Iulius Felix ${ }^{85}$ (fig. 20), con la que comparte las proporciones y el empleo de diferentes tipos de piedra local. De esta manera, tomando este altar como referencia, calculamos que el cuerpo de nuestro monumento sería de aproximadamente seis veces la altura del capitel, al que sumaríamos todas las medidas que tenemos, según la disposición que nos parece más lógica, dando una altura aproximada de $5 \mathrm{~m}$. De esta forma, según la reconstrucción que ahora proponemos, nuestro monumento quedaría dispuesto sobre un zócalo de 2 escalones, sobre el que se levantaría un edificio cuya base sería de $2,90 \mathrm{~m}$ por 3,25 ó $3,90 \mathrm{~m}$, según las diferentes reconstrucciones, con una altura aproximada de $5 \mathrm{~m}$.

${ }^{85}$ En las campañas que se han realizado hasta la actualidad no se han recogido restos de basa, ni de fuste estriado ni de arquitrabe; sin embargo, atendiendo a la similitud que presenta nuestro monumento con el de Iulius Felix (cf. nota 12), hemos creido conveniente incluir en la reconstrucción sólo el fuste estriado.
En relación con la reconstrucción, varios problemas nos quedan por resolver; por una parte pensamos que el monumento tendría una puerta de acceso a la cámara sepulcral ${ }^{86}$, ya que su propietaria parece ser que se lo construyó en vida, para ella y para otras personas. La inscripción funeraria de Domitia Iusta se recuperó en el foso que existe excavado en la fachada noreste, por lo que sería lógico pensar que la puerta estuviese allí; si así fuera, ésta se situaría de espaldas a la vía, que discurriría por la parte abierta del valle, lo que nos parece una contradicción cuando lo que se intenta perpetuar, con la construcción del monumento, es el nombre del difunto ${ }^{87}$. Una

80 Varios fragmentos de pared estucada, en color blanco, se recuperaron en el estrato removido por el arado junto con restos del monumento.

${ }^{87}$ M. L. Cancela y M. Martín-Bueno, «Hispanie romaine: architecture funéraire monumentale dans le monde rural", Monde des morts, monde des vivants en Gaule rural, Actes du Colloque $A R C H E A / A G E R$, Tours, 1993, p. 408. 


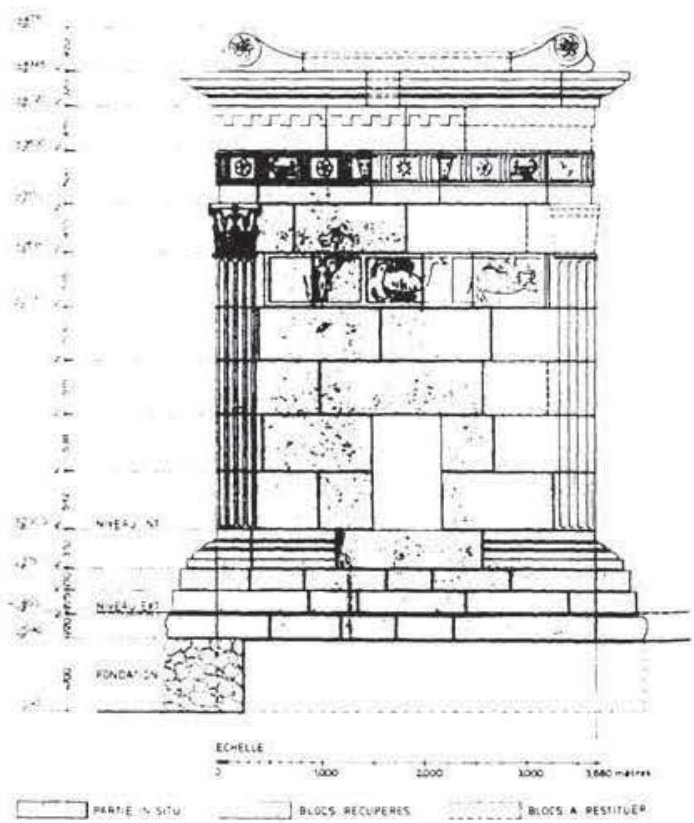

Figura 20.-Parte frontal del monumento funerario de lulius Felix, tomado de Ferchiou (op. cit. nota 18), p. 420.

solución que proponemos es que en el monumento se repitieran los epigrafes en la fachada suroeste, visible desde el camino, como ocurre en la pirámide de $C$. Cestius $^{\mathrm{xx}}$ de Roma, en el monumento de $L$. Poblicius Bibulus ${ }^{84}$ de Colonia o como podría ocurrir en la Iglesuela del $\mathrm{Cid}^{\% 0}$, teniendo de esta manera nuestro monumento dos fachadas similares, con la puerta de acceso en la más sombría.

\section{EL PROPIETARIO DEL MONUMENTO}

La parte conservada de la inscripción del monumento nos revela la identidad de la propietaria y poco más; por ella sabemos que Domitia Iusta construyó el monumento para si y, presumiblemente, para otros miembros de su familia, según se desprende de la fórmula sibi et.

Por la filiación de la inscripción, sabemos que su padre se llamaba Lucio, lo cual no tiene nada de particular teniendo en cuenta que éste es uno de los praenomina más utilizados por esta gens.

La gens Domitia, a la que pertenecía Iusta, está

\footnotetext{
${ }^{88} \mathrm{G}$. Lugli, I monumento antichi di Roma e suburbio, Roma 1927.

${ }^{89}$ G. Precht, Das Grabmal des L. Poblicius, Köln, 1975.

${ }^{90}$ F. Arasa, op. cit. nota 33, p. 169.
}

documentada en las diversas provincias de Hispania $^{91}$. En la parte meridional del convento Tarraconense es la undécima vez que la encontramos y es curioso constatar que se aprecia una localización predominantemente interior de estos testimonios. Por ello, no seria extraño que la gens Domitia, atestiguada en la comarca de Requena-Utiel, hubiese estado emparentada o relacionada con la que se documenta en el monumento funerario de la Iglesuela del Cid; los motivos que permiten presumir una relación van más allá del uso de un mismo nomen, ya que como hemos visto el monumento de esa localidad también era un ara rematada con pulvini y las inscripciones que se conservan de los dos monumentos están delimitadas por volutas espiraliformes.

Un elemento que también estrecha las posibles relaciones entre ambas áreas es el uso del cognomen Seranus, el cual, siendo bastante raro en Hispania, lo encontramos en La Iglesuela del Cid ${ }^{92}$ y dos veces en la comarca de Requena Utiel: en Sinarcas $^{03}$ y en Venta del Moro ${ }^{44}$. En Jorquera (Albacete), en la inscripción que ya hemos citado, que también utiliza las volutas espiraliformes, idénticas a las nuestras, se documenta también dos veces Serranius, una variante de este mismo cognomen"s.

Iustus, sin ser un cognomen raro, tampoco es de los corrientes; para Hispania, los indices de Abas$\mathrm{cal}^{96}$ lo documentan en treinta y una personas, de las cuales nueve pertenecen al País Valenciano. De todos los casos atestiguados en Hispania, ninguno de ellos pertenece a la gens Domitia y de las personas que lo utilizaron fuera de ella, sólo en tres ocasiones, que sepamos, el nomen era Domitia/us, dos mujeres en Aquileia ${ }^{97}$ y un hombre en Sessa (Italia) ${ }^{98}$.

\section{EL MONUMENTO DENTRO DE LA NECRÓPOLIS}

El monumento funerario de Domitia Iusta creemos que fue el origen de la necrópolis de incinera-

${ }^{91}$ E. Hübner, Corpus Inscriptionum Latinarum, Berlin, 1869, tomo II, p. 1061; R.C. Knapp, Ancient Society 9, 1978, p. 211; J. M. Abascal, Los nombres personales en las inscripciones latinas de Hispania, Murcia 1994, pp. 129-130.

${ }^{92}$ F. Arasa, op. cit. nota 33, p. 159.

${ }^{43}$ CIL II 4449.

${ }^{94}$ A. Martinez Valle, «Dos nuevas inscripciones de la comarca Requena-Utieln, Saguntum 25, 1992, pp. 109-203.

${ }^{45}$ J. M. Abascal, 1990, op. cit. nota 64, p. 40.

06 J. M. Abascal, 1994, op. cit. nota 91 p. 393.

${ }^{97}$ CIL V, 984 y 1194

${ }^{98} \mathrm{CIL} \mathrm{X}, 4767$. 

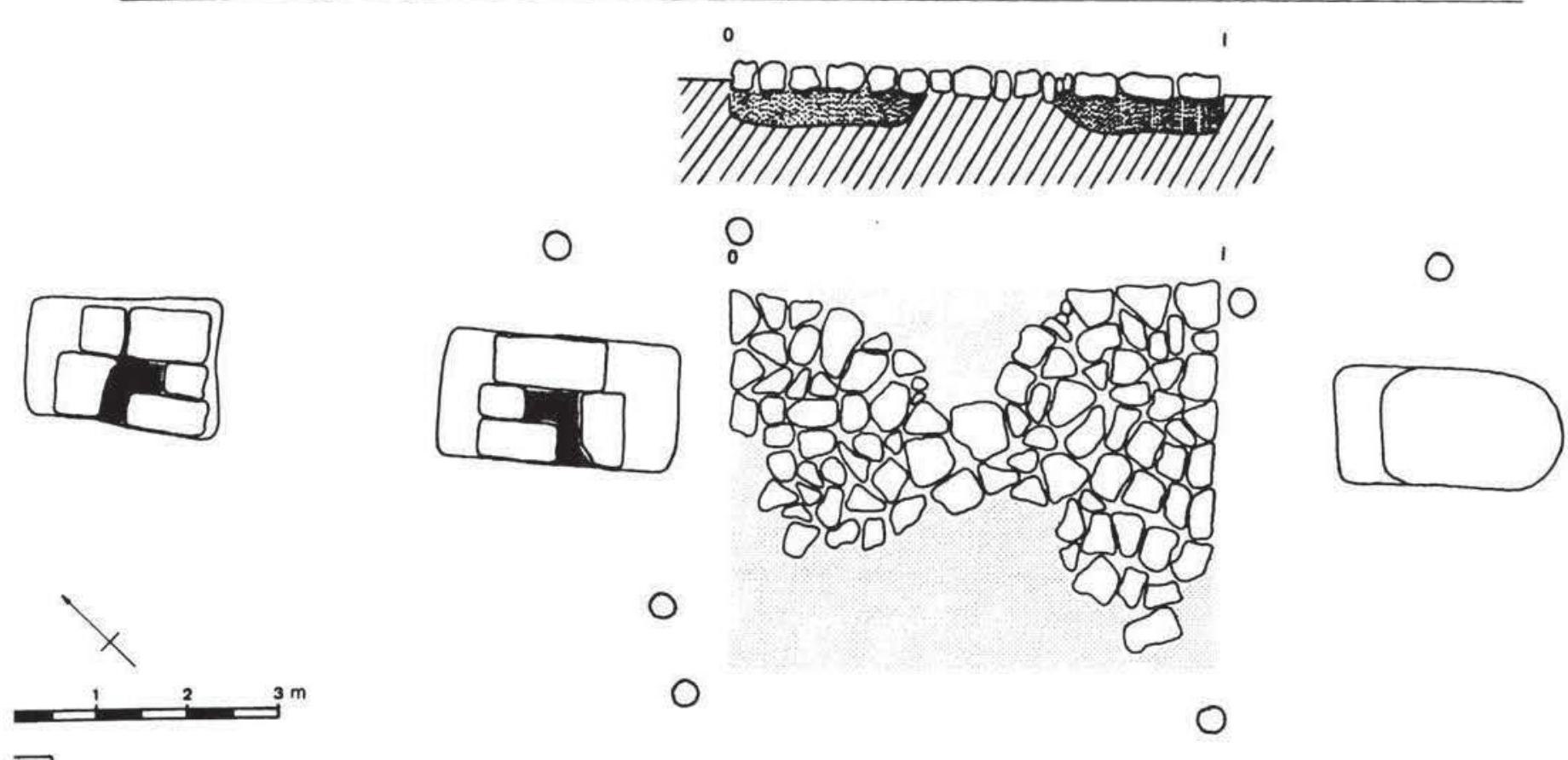

Figura 21.-Planimetria del monumento con tres tumbas de cremación adosadas a él. Trama A: reconstrucción de la planta: Trama B: loculi de las tumbas de incineración.

ción que se desarrolló en su entorno y que constituye un interesante ejemplo de organización espacial dentro de un recinto funerario ${ }^{49}$.

Las tumbas más importantes de esta necrópolis de incineración se alinearon junto al ara de lusta, suponemos que para realzar su importancia, dando lugar a una mayor monumentalidad del conjunto (fig. 21).

El esquema espacial que documentamos en La Calerilla está presente en un buen numero de necrópolis del imperio romano a partir del siglo । d.C., como puede verse en el norte de Italia, en Aquileia ${ }^{100}$, y en zonas bien romanizadas como la Narbonense o Aquitania ${ }^{101}$; en todos estos casos un ara monumental, dentro de un recinto delimitado por muros, aparece rodeada de varias tumbas más modestas reproduciendo un esquema similar al que se documenta en Roma para el cenotafio de Agripa ${ }^{102}$.

\footnotetext{
${ }^{90} \mathrm{El}$ estado en que se encuentra la excavación en la actualidad no permite determinar la extensión exacta de la necrópolis. En anteriores campañas se ha aislado totalmente un muro que discurre paralelo al monumento por su lado norte. Otro muro de idénticas características a este excavado, se ha documentado en un pequeño sondeo realizado en el lado este del campo, lo que nos permite suponer la posibilidad de que exista un recinto funerario.

${ }^{100}$ G. Brussin, Nuovi monumenti sepolcrali di Aquileia. Venezia, 1941.

101 Ch. Nerzic, La sculpture en Gaule romaine, Paris, 1989. p. 215.

${ }^{102}$ E. La Rocca, op cit. nota 75, p. 90.
}

En el caso de la necrópolis de La Calerilla, las tumbas que se adosan al monumento de Domitia lusta son varios busta sobre los que se construyeron pequeños monumentos realizados con grandes bloques de caliza gris; éstos ocupan parte del espacio de la fosa que se excavó para realizar la incineración y se sitúan en línea, con la misma orientación que tenía el ara principal y el muro que discurre paralelo a estas tumbas, en su lado noreste. Suponemos que estos monumentos, tendrian una proyección vertical, pero desconocemos la altura que alcanzarían al encontrarse ya muy arrasados en el momento de la excavación.

Estas tumbas, de igual manera que el monumento principal de la necrópolis, fueron profanadas en un momento indeterminado ${ }^{103}$. Alguna de ellas se encontró prácticamente vacía, quedando tan sólo la fosa de incineración bien marcada por la rubefacción de la pira, los bloques de caliza delimitando el loculus y el material procedente del arrastre, que colmató la tumba.

Uno de estos busta, el más alejado del monu-

\footnotetext{
${ }^{103}$ Las tumbas de inhumación que hemos excavado en esta necrópolis no muestran indicios de destrucción por lo que suponemos que en el período que se dejó de utilizar la necrópolis y se pasó del rito de la incineración a la inhumación se produciría esta destrucción.
} 

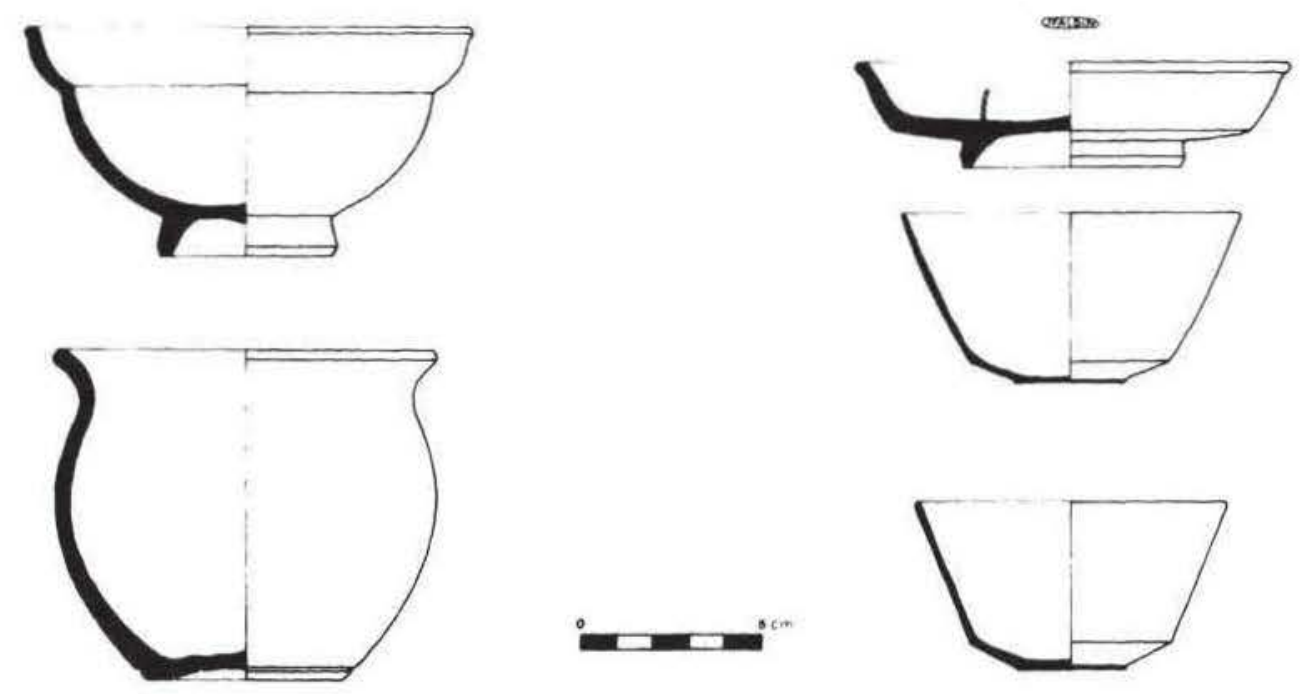

Figura 22. - Cerámicas procedentes de la tumba de cremación n*3 (U.E. 1117 ).

mento, se ha mantenido en un buen estado a pesar de estar como todos profanado. Desconocemos la composición original del ajuar funerario que contendria, pero aún conservaba los restos de la urna cineraria ${ }^{104}$ en la parte superior de la fosa, fracturada, pero bastante completa, junto con una buena parte de las cerámicas depositadas en la incineración. La excavación de esta tumba proporcionó, junto a estos restos, un buen número de materiales que habian sido arrojados a la pira funeraria, encontrándose bastante completos entre las cenizas, los carbones y los huesos quemados que permanecieron bajo el monumento, después de haberse llevado a cabo la cremación.

Los materiales que ha proporcionado esta tumba son cerámicas sigillatas ${ }^{105}$ y recipientes de "cascara de huevo" ${ }^{106}$ que, si bien no nos permiten concretar mucho la cronología si nos sitúan en torno a la época flavia (fig. 22). Las sigillatas recuperadas en esta incineración están bastante fracturadas, con indicios de haber estallado por las altas temperaturas; éstas cerámicas fueron arrojadas al fuego en el momento en que se llevó a cabo la cremación y cons-

\footnotetext{
${ }^{104}$ La urna es de la forma 67 de Isings, fechadas a partir del siglo I d.C. véase C. Isings, Roman Glass from Dated Finds, Groningen/Djakarta, 1958.

10s Cerámicas sigillatas de procedencia sudgálica, una copa de la forma Drag. 27 y un plato de la forma Drag. 36, véase C. Bemont, La terre sigillée gallo-romaine. Lieux de production de Haut Empire: implantatios, produits, relations, Paris, 1980, D. A. F. $n^{\circ} 6$.

${ }^{106}$ Las cerámicas denominadas "cáscara de huevon son de la forma 34A de Mayet, fechadas a partir de Claudio-Nerón, véase F. Mayet, Les céramiques à parois fines dans la Péninsule lbérique, Paris, 1975, p. 69, y J. A. Minguez, La cerámica ramana de paredes finas, Zaragoza, 1991, p. 88.
}

tituyen un interesante término ante quem para el momento de construcción del monumento funerario de Domitia lusta. Si como suponemos estas cremaciones se fechan en torno a la época flavia, entonces el monumento funerario de Domitia lusta, que fue el que dio origen a esta necrópolis de incineración ha de datarse con anterioridad a ellas.

\section{MONUMENTOS DE ALTAR EN LA PENINSULA IBÉRICA}

Los monumentos que Mansuelli denomina «ad altare" ${ }^{177}$ tienen su origen en los monumentos de dado, con los que a menudo se identifican en la bibliografia, cuyo ejemplo más antiguo conocido, situado al pie del Aventino, es el dedicado a Sulpicius Galba, cónsul en el año 108 a.C. ${ }^{108}$. Esta estructura cuadrangular, se irá revistiendo de elementos arquitectónicos pseudofuncionales y elementos decorativos diversos, adquiriendo así unas características concretas que la definirán como tipo.

Los monumentos de altar están bien representados en las necrópolis de Italia Central de mediados del siglo I a.C., extendiéndose hacia el norte por el valle del Po, siguiendo las principales vías de comunicación y asociados con la colonización romana. Desde Italia se producirá una expansión de este tipo de monumentos hacia las provincias occidentales, llegando a Hispania en el siglo I d.C. como un

${ }^{107}$ G. Mansuelli, «Monumento funerario» EAA, V, Roma, 1963 , p. 194.

${ }^{108} \mathrm{~B}$. Felletti, La tradizione italica nell' arte romano, Roma, 1977. 
modelo más de entre la tipologia de monumentos funerarios.

Los altares funerarios suelen estar asociados a unas características que los definen, como son los frisos dóricos, el estar asociados a recintos funerarios o su remate con pulvini. Frente a estas caracteristicas generales, existen otros monumentos funerarios cuyo primer cuerpo viene constituido por un dado y no se rematan con pulvini, pudiéndose coronar de diferente forma ${ }^{104}$; también se conocen otros altares con pulvini que no presentan friso dórico, como la tumba de las guirnaldas de la vía Apia ${ }^{110} \mathrm{O}$ la de Cartilius Poplicola de Ostia "I'; por lo que pensamos que el único elemento que con seguridad los identifica es su remate con pulvini.

Los monumentos de altar, no han sido objeto de la suficiente atención por parte de los investigadores hasta hace pocos años, ya que, por lo general, se encuentran muy deteriorados y los pulvini, que son los elementos que los identifican, han sido reutilizados y descontextualizados en la mayoria de los $\operatorname{casos}^{112}$, por lo que falta todavia un estudio más profundo y una sistematización de los mismos ${ }^{113}$.

En la peninsula ibérica, Balil fue el primero que estudió el grupo de altares catalanes ${ }^{114}$, posteriormente Gamer haria una revisión a nivel peninsu$\operatorname{lar}^{115}$, siendo el estudio publicado por Beltrán Fortes $^{116}$, el último que se ha realizado, en el que da a conocer los nuevos materiales recuperados en la Alta Andalucia. En este último trabajo, se efectúa un completo análisis del tema y una revisión de la bibliografia, por lo que no es nuestra intención volver a incidir sobre estos aspectos y, en consecuencia, remitimos al lector a esa publicación para todo lo concerniente a los origenes de este tipo de monumento, a su desarrollo y a su extensión por el imperio ${ }^{117}$.

En la peninsula ibérica se conocen bastantes pulvini monumentales, descontextualizados en su

\footnotetext{
${ }^{100} \mathrm{~L}$. Abad, "La torre ciega de Cartagena", Homenaje al prof. A. Blanco Freijeiro, Madrid 1989, p. 251.

${ }^{110}$ M. Eisner, Zur Typologie der Grabbaueten in Suburbium Roms, Roma, 1986.

11 F. Squarciapino, op. cit. nota 71 .

112 En la península ibérica existió un ara monumental en Dehesa de Baños cuyos pulvini fueron reutilizados como columnas en una villa del Bajo Imperio, véase M. L. Cancela, op. cit. nota 56, p. 252.

ii) E. La Rocca, op. cit. nota 75, p. 92.

"A. Balil, "Los Gorgoneia de Barcinon, Faventia I, 1, 1979, pp. $63-70$.

i1s G. Gamer, op. cit. nota 76.

$116 \mathrm{~J}$. Beltrán Fortes, op. cit. nota 52, p. 183-226.

"' Recientemente M. L. Cancela ha defendido su tesis doctoral sobre la arquitectura funeraria de Hispania romana, que todavía no ha sido publicada y que esperamos que aclare este aspecto del mundo funerario; un avance de su trabajo se presentó en unos cursos de la UIMP en Sagunto, en Septiembre de 1992.
}

mayor parte, con una concentración en cuatro zonas diferenciadas: Alta Andalucia, Segobriga ${ }^{11 x}$, Barcelona y en Portugal, en torno a Idanha a Velha ${ }^{114}$. Frente a estos focos, que parecen documentar una mayor utilización de altares, existen algunos ejemplares y fragmentos aislados que demuestra que este tipo de monumentos tuvo su clientela en Hispania, al igual que en otras zonas romanizadas del imperio.

De todo este grupo de pulvini, que pertenecerian a altares monumentales, tan sólo en un caso, que sepamos, se puede asociar a un monumento concreto, se trata de la tumba de los Domitii de la Iglesuela del $\mathrm{Cid}^{120}$. Este monumento, reutilizado para la construcción de la ermita de la Virgen del Cid, ha conservado completo e in situ el perfil del basamento y una parte del cuerpo principal con la cornisa. Los pulvini, el capitel, varias inscripciones y diferentes elementos decorativos, que pertenecerian al friso, se encuentran repartidos en la estructura de la nueva construcción. Además de este ara monumental, parcialmente conservada, existiría el altar desmontado de Dehesa de Baños ${ }^{121}$, cuya forma y decoración desconocemos y un monumento funerario de Segobriga que también estaría decorado con pilastras y capiteles corintios y que en opinión de L. Baena se podria relacionar con alguno de los pulvini procedentes de este lugar ${ }^{122}$. Aparte de estos monumentos, existen dos reconstrucciones en el museo de Barcelona y el modelo que propone Beltrán Fortes para la zona andaluza, a base de diversos fragmentos aislados (fig. 23).

Las reconstrucciones de altares del museo de Barcelona, uno con pulvini con alargamientos laterales y el otro con pulvini cilindricos exentos, muestran formas simples sin mucha decoración, con gorgoneion en el frente de los pulvini en los dos casos, similares a altares conocidos en la Narbonense, como el de Aemilia de Nimes, o en Italia, como la tumba de los Alleii de Pompeya, y tienen poca similitud estilistica con el que estamos estudiando. La fecha propuesta para ellos oscila desde época flavia hasta finales de época severa, sin que de momento se haya podido precisar más la cronología.

En Andalucía, como ya hemos comentado, existe un abundante grupo de pulvini, asociados a necrópolis urbanas, con una mayor concentración en la zona de Jaén. A partir de la reconstrucción que

"1" L. Baena del Alcazar, "Monumentos funerarios romanos de Segobriga", Homenaje a Balil, Málaga, pp. 147-161.

$119 \mathrm{G}$. Gamer, op. cit. nota 76.

${ }^{120}$ F. Arasa, op, cit. nota 33, p. 141-179.

${ }^{121}$ M. L. Cancela, 1993, op. cit. nota 56 p. 252.

${ }^{122}$ L. Baena del Alcazar, op. cit, nota 118, p. 155. 

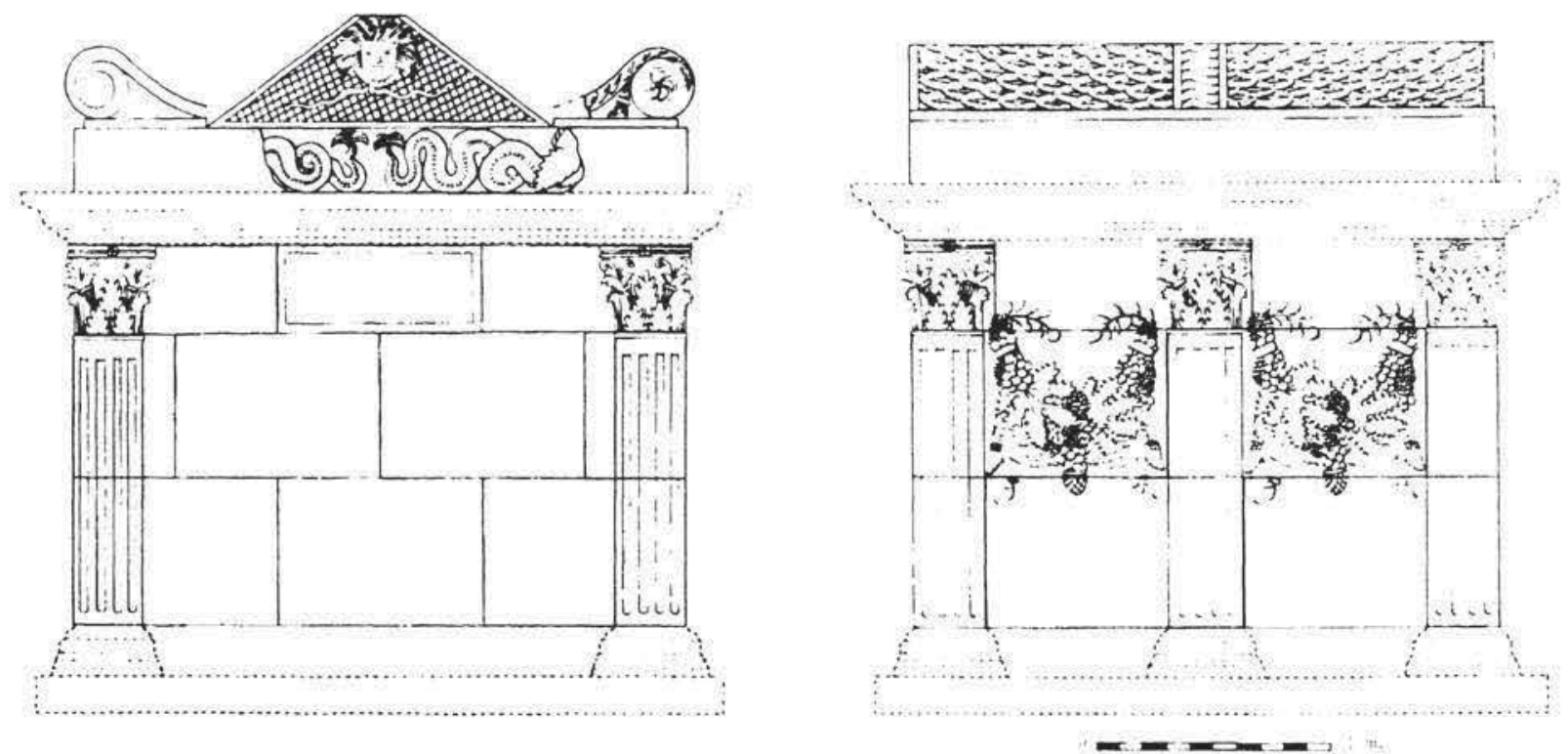

Figura 23.- Reconstrucción de un altar de la Alta Andalucia, tomado de Beltrán Fortes (op. cit. nota 62), p. 207.

propone Beltrán Fortes, este grupo de altares tendría poca relación tipológica con el grupo catalán. La diferencia de los altares andaluces estriba en que son más recargados que los catalanes, ya que van adornados con capiteles, pilastras, guirnaldas y motivos vegetales.

Entre los pulvini de los altares andaluces, Beltrán piensa que existió un frontón triangular con gorgoneion y con un friso decorado con temas marinos, encontrando los paralelos más similares para este grupo andaluz en ejemplares germanos, más concretamente del grupo de Niimagen. Para nosotros, el frontón triangular pertenecería a otro tipo de monumento funerario, posibilidad que ya señala el autor ${ }^{123}$, como pueden ser edículas o estelas, donde están bien representados los frontones que van decorados con diferentes elementos alusivos al mundo funerario ${ }^{124}$, entre los que se encuentra la Gorgona, como en el caso de los frontones andaluces.

En altares monumentales, la asociación entre pulvini y frontones se da con frecuencia en los casos en que los pulvini presentan alargamientos laterales, pero en los casos que conocemos, el frontón

${ }^{123} \mathrm{~J}$. Beltrán, op. cit. nota 52, p. 202.

${ }^{124} \mathrm{~L}$. Abad, « El relieve romano de Coves de Vinromà (Castellón)", Lucentum V, 1986, pp. 119-136, donde se da una extensa relación de monumentos imperiales que presentan este tipo de frontones; en la Peninsula Ibérica se conservan fragmentos de un monumento con frontón triangular procedente de Mérida, véase J. F. Rodriguez Neila y F. Chaves Tristan, "Un monumento funerario procedente de Emeritan, Habis 4, 1973, pp. 295-311. no suele sobrepasar la altura de éstos ${ }^{125}$. La asociación entre pulvini y frontones se puede observar mejor en los altares pequeños, donde es más elevado el porcentaje de casos en los que el frontón no sobrepasa la altura de los pulvini. Los frontones triangulares aparecen a menudo con acróteras laterales y en esos casos si es frecuente que el frontón sobrepase la altura de las acróteras.

De esta manera, si eliminamos el frontón triangular de la reconstrucción que propone Beltrán Fortes, los altares andaluces quedarían más emparentados con los ejemplares itálicos decorados con capiteles, pilastras, guirnaldas etc., que con los del grupo de Niimagen. De hecho, las similitudes con los temas decorativos y la iconografia funeraria de tradición helenística que presentan los monumentos de Niimagen y de Andalucia, también se pueden observar en monumentos funerarios de todo el imperio romano durante el siglo I d.C.

En cuanto al altar funerario de La Calerilla, por la decoración que se ha conservado, estaría más próximo a los ejemplos andaluces que a los altares del noreste peninsular, si bien sus dimensiones son mayores que las propuestas por Beltrán Fortes. Por otra parte, teniendo en cuenta la diferencia de diámetros en el grupo de pulvini andaluces ${ }^{126}$, podría-

\footnotetext{
125 Véanse los altares de Niimagen que aparecen con fronton triangular entre los pulvini pero que no sobrepasan la altura de estos. Massow, 1932, op. cit. nota 42, pp. 38 y 113 y E. Esperandieu, op. cit. nota 40 , el $\mathrm{n}^{\circ} 5174$ y n $^{\circ} 5177$.

126 J. Beltrán, op. cit. nota 52, p. 223.
} 
mos pensar que existirian, en la zona de Jaén, altares similares al de la Calerilla, ya que los motivos decorativos, el uso de piedra local o las caracteristicas de la labra, asi parecen apuntarlo.

La relación entre la zona de la Alta Andalucia y la Citerior en los últimos tiempos del periodo republicano y la época imperial ha sido señalada por diferentes autores en diversos tipos de estudios ${ }^{12}$. Gamer señala relaciones entre un taller de Tarraco y monumentos funerarios de Iliturgi ${ }^{128}$, por lo que no es de extrañar que estas relaciones influyeran, de alguna manera, en la construcción de nuestro monumento funerario; los hallazgos numismáticos de la comarca de Requena-Utiel también avalan esta hipótesis, al estar bien presentes en yacimientos ibéricos las monedas de cecas andaluzas y muy especialmente las de Cástulo y Obulco ${ }^{129}$.

\section{CONCLUSIONES}

De todo cuanto se ha expuesto en las lineas precedentes, se desprende que a mediados del siglo I d.C. y en un medio rural, Domitia lusta construyó para si y presumiblemente para sus familiares un monumento funerario en forma de altar, rematado con pulvini. El altar estaría orientado en dirección noreste-suroeste, se levantaría sobre un zócalo de dos escalones, estuvo decorado con pilastras que se remataban con capiteles y contaba con un friso, molduras y cornisas. Tendría aproximadamente una altura de $5 \mathrm{~m}$, un ancho de 3,25 ó $3,90 \mathrm{~m}$ y una profundidad de $2,90 \mathrm{~m}$.

En la cara noreste es probable que estuviera la puerta de acceso y sobre ella se dispondrian, al menos, dos campos epigráficos enmarcados con volutas espiraliformes y sustentados por erotes. En uno de ellos, el que se ha conservado, se menciona la identidad de la propietaria y alude a que fue concebido también para albergar a otras personas, cuya identidad no conocemos, al no haberse conservado nada del segundo campo epigráfico.

\footnotetext{
127 G. Gamer, "La "Torre de los Escipiones" y otros monumentos funerarios sucesores del Mausoleo de Halicarnaso «, BSAA XLVII, 1981, pp. 71-87. M. P, García-Bellido, Las monedas de Castulo con escritura indigena, Barcelona, 1982. P. P. Ripollés Alegre, La circulación monetaria en la Tarraconense Mediterránea, Trabajos Varios 77, 1982.

${ }^{128} \mathrm{G}$. Gamer, op. cit. nota 127, p. 82.

${ }^{129}$ P. P. Ripollés Alegre, «Estudio numismático del poblado ibérico de Los Villares (Caudete de las Fuentes, Valencia)", Numisma, 165-167, 1980, pp. 9-22. R. Arroyo llera y otros «Aproximación a la circulación monetaria de las comarcas interiores de la provincia de Valenciam, Saguntum 22, 1989, pp. 363. 391.
}

Poco tiempo después de la construcción del monumento, se dispusieron a su derecha e izquierda una serie de incineraciones con superestructura, alineadas con el monumento, por lo que suponemos que la necrópolis experimentó un periodo de expansión, seguramente originado por la atracción que ejerció el monumento de Domiria lusta.

El horizonte cronológico en el que se construyó este monumento creemos que ha de situarse a mediados del siglo । d.C. Las características paleográficas y estructurales de la inscripción, la labra de los elementos de adorno y el tipo de monumento que se construyó Domitia lusta parecen avalarlo.

Los pequeños monumentos que acompañan al ara de Domitia lusta nos aproximan con más fiabilidad a su momento de construcción; éstos se erigieron sobre sus busta, que por el tipo de cerámicas que contenian, arrojadas al fuego en el momento de efectuarse la incineración del cadáver, consideramos que pudieron haber sido construidos en el periodo flavio. El hecho de que el monumento de Domitia lus$t a$ se construyera mientras vivia, nos impide determinar con precisión los años que separarian a este monumento de las otras tumbas de incineración, bien datadas y que se adosan a él, pero el esquema que los artesanos siguieron para la construcción del monumento de lusta sigue tendencias de modelos en boga en época julio-claudia.

El monumento funerario de Domitia lusta, nos plantea una serie de cuestiones relacionadas con su tipologia y su ubicación muy interesantes. La generalización de estos monumentos en torno a las vías de comunicación ${ }^{130}$, nos lleva a creer que por el valle de Hortunas existiese una vía de penetración, ya en época ibérica, que comunicara la costa con el altiplano de Requena-Utiel, antesala de la meseta, lo que explicaria la cantidad de yacimientos ibéricos del valle y la ubicación de oppida, como La Carencia de Turís o El Pico de los Ajos de Yátova, junto al río Magro ${ }^{131}$. Por otra parte, la ubicación de este monumento en una zona alejada de centros urbanos, donde la tradición ibérica es bien patente ${ }^{132}$, nos daria pie para suponer que altares con pulvini similares al nuestro se construirían en zonas más romanizadas de la Alta Andalucía o del noreste peninsular, ya en el período julio-claudio.

\footnotetext{
${ }^{130}$ M. L. Cancela y M. Martín-Bueno, op. cit. nota 87, p. 401

13 J. Bernabeu y otros, "Hipótesis sobre la organización del territorio edetano en época ibérica plena: el ejemplo del territorio de Edeta/LLirian, Iberos. Actas de las I Jornadas sobre el Mundo Ibérico, Jaén, 1985, pp. 137-156.

${ }^{132}$ M. L. Cancela y M. Martin-Bueno, op. cit. nota 87, p. 401.
} 